\title{
Measuring the Performance of Attention Networks with the Dalhousie Computerized Attention Battery (DalCAB): Methodology and Reliability in Healthy Adults
}

\author{
Stephanie A. H. Jones ${ }^{1 *}$, Beverly C. Butler ${ }^{1,2}$, Franziska Kintzel ${ }^{1}$, Anne Johnson ${ }^{1}$, \\ Raymond M. Klein ${ }^{3}$ and Gail A. Eskes ${ }^{1,4 *}$ \\ ${ }^{1}$ Cognitive Health and Recovery Research Laboratory, Department of Psychiatry, Dalhousie University, Halifax, NS, Canada, \\ ${ }^{2}$ Research Services, Nova Scotia Health Authority, Halifax, NS, Canada, ${ }^{3}$ Cognitive Science Laboratory, Department of \\ Psychology and Neuroscience, Dalhousie University, Halifax, NS, Canada, ${ }^{4}$ Affiliated Scientist, Medical Staff, Nova Scotia \\ Health Authority, Halifax, NS, Canada
}

\section{OPEN ACCESS}

Edited by:

Andriy Myachykov,

Northumbria University, UK

Reviewed by:

Juan Lupiáñez,

University of Granada, Spain

Nikolay Novitskiy,

National Research University Higher

School of Economics, Russia

*Correspondence:

Stephanie A. H. Jones stephaniejones03@hotmail.com

Gail A. Eskes

gail.eskes@dal.ca

Specialty section: This article was submitted to

Cognition,

a section of the journal

Frontiers in Psychology

Received: 25 January 2016 Accepted: 17 May 2016

Published: 07 June 2016

Citation:

Jones SAH, Butler BC, Kintzel F, Johnson A, Klein RM and Eskes GA (2016) Measuring the Performance of Attention Networks with the Dalhousie

Computerized Attention Battery (DalCAB): Methodology and Reliability in Healthy Adults.

Front. Psychol. 7:823

doi: 10.3389/fpsyg.2016.00823
Attention is an important, multifaceted cognitive domain that has been linked to three distinct, yet interacting, networks: alerting, orienting, and executive control. The measurement of attention and deficits of attention within these networks is critical to the assessment of many neurological and psychiatric conditions in both research and clinical settings. The Dalhousie Computerized Attention Battery (DalCAB) was created to assess attentional functions related to the three attention networks using a range of tasks including: simple reaction time, go/no-go, choice reaction time, dual task, flanker, item and location working memory, and visual search. The current study provides preliminary normative data, test-retest reliability (intraclass correlations) and practice effects in DalCAB performance 24-h after baseline for healthy young adults ( $n=96$, 18-31 years). Performance on the DalCAB tasks demonstrated Good to Very Good test-retest reliability for mean reaction time, while accuracy and difference measures (e.g., switch costs, interference effects, and working memory load effects) were most reliable for tasks that require more extensive cognitive processing (e.g., choice reaction time, flanker, dual task, and conjunction search). Practice effects were common and pronounced at the 24-h interval. In addition, performance related to specific within-task parameters of the DalCAB sub-tests provides preliminary support for future formal assessment of the convergent validity of our interpretation of the DalCAB as a potential clinical and research assessment tool for measuring aspects of attention related to the alerting, orienting, and executive control networks.

Keywords: computerized assessment, attention, orienting, alerting, executive function

\section{INTRODUCTION}

Attention is a multifaceted cognitive domain that is required for efficient perception, learning, memory, and reasoning. Different aspects of attention have been conceptualized in a number of models, such as Theory of Visual Attention (TVA, a computational model of selective attention, Bundensen, 1990), Working Memory (Baddeley and Hitch, 1974, updated in Baddeley, 2012), 
Cowan's information processing model (Cowan, 1988, 1998) and the attentional trace model of auditory selective attention (Naatanen, 1982). These, and other aspects of attention were integrated into a neurocognitive framework of an attention system that involves separate but interacting attentional brain networks underlying the attentional functions of alerting, orienting (selection), and executive control (e.g., Posner and Petersen, 1990; Fan et al., 2002; Petersen and Posner, 2012). Alerting or vigilance refers to the ability to develop and sustain a state of mental readiness, which consequently produces more rapid selection, detection, and responses to relevant stimuli in the environment (Posner and Petersen, 1990). The alerting system has been measured with continuous performance and vigilance tasks in which the participant is asked to continuously respond to sequentially presented stimuli with or without warning signals prior to the target (phasic alertness vs. tonic alertness); these tasks are thought to activate right hemisphere frontal and dorsal parietal regions related to the neuromodulator norepinephrine (c.f. Sturm and Willmes, 2001; Petersen and Posner, 2012 for a full review). The orienting of attention involves the selection of a stimulus or spatial location in the environment in order to process that information more fully. Orienting attention requires that attention be disengaged from its current focus, moved, and then re-engaged on the selected location/stimulus. While Posner's original orienting system was associated with cholinergic systems involving the frontal lobe, parietal lobe, superior colliculus, and thalamus (Posner et al., 1982; Posner and Petersen, 1990), recent evidence argues for two separate but interacting orienting networks: (1) a bilateral dorsal system including the frontal eye fields and intraparietal sulci related to rapid strategic control over attention and; (2) a strongly right-lateralized ventral system including the temporoparietal junction and ventral frontal cortex related to breaking the focus of attention and allow switching of attention to a new target (Corbetta and Shulman, 2002; Petersen and Posner, 2012). Spatially-cued target detection tasks and visual search tasks are typically used to assess attentional orienting. Finally, in terms of executive control function, evidence indicates the presence of at least two relatively independent executive networks: (1) a fronto-parietal network, distinct from the orienting network, that is thought to relate to task initiation, switching, and trialby-trial adjustments, and; (2) a midline cingulo-opercular and anterior insular network related to maintenance across trials and maintenance of task performance as a whole, i.e., set maintenance, conflict monitoring, and error feedback (Petersen and Posner, 2012, see Figure 2B; Dosenbach et al., 2007, see Figure 4).

Given the above framework and the overarching effect that attentional impairment can have on the successful completion of day to day activities and overall quality of life (e.g., Bronnick et al., 2006; Barker-Collo et al., 2010; Cumming et al., 2014; Middleton et al., 2014; Torgalsbøen et al., 2015), valid and reliable measurement of attention is important for addressing attention impairment in both research and clinical care of psychiatric and neurologic patients. While most standardized "paper-andpencil" measures used in the neuropsychological assessment of attention allow comparison of an individual's performance to a healthy normative sample (as well as patient samples), it can be difficult to isolate specific domains of attention as conceptualized in Posner's model per se (e.g., Chan et al., 2008). Therefore, a supplementary or alternative procedure to standardized neuropsychological testing is necessary to provide reliable and sensitive assessment of attentional function. Computer-based cognitive testing procedures have been developed as one option.

The Attention Network Test (ANT; Fan et al., 2002) is one such computerized measure of attention designed to quantify the efficiency of the vigilance, orienting and executive control networks through the combination of a cued reaction time task (Posner, 1980) and a flanker task. Participants are instructed to respond to the direction of an arrow stimulus flanked by congruent, incongruent, or neutral stimuli, following the presentation of one of four cue conditions. Difference values between the various cue and flanker conditions can be used as a quantitative measure of the efficiency of the vigilance, orienting, and executive control attention networks (cf Fan et al., 2002 for a full review). Subsequent versions of the ANT also allow an assessment of the interactions among the attention networks (ANT-Interactions, Callejas et al., 2005; ANTRevised, Fan et al., 2009). The ANT and ANT-I have been used in a variety of populations, including children, healthy adults of varying ages, and a variety of clinical populations and allow for comparisons across attentional networks due to their integrated nature and brevity (Fernandez-Duque and Black, 2006; Adolfsdottir et al., 2008; AhnAllen et al., 2008; Ishigami and Klein, 2010; Ishigami et al., 2016; see review in MacLeod et al., 2010). While use of the ANTs has proved valuable for exploration of attention mechanisms in normal and clinical populations, there are limitations to these tests. In order to limit test time, the assessment of alerting, orienting, and executive control is dependent upon a single difference measure producing a network score, with alerting and orienting network RT scores showing lower than ideal reliability across studies (ranging from 0.20 to 0.61 ) and the executive network RT score showing better reliability (ranging from 0.65 to 0.81; Fan et al., 2002; MacLeod et al., 2010). In addition, investigations of the validity of the ANT are limited, but Ishigami et al. (2016) found that while the executive network score was a significant predictor of conflict resolution, and verbal memory retrieval, no associations were found between the alerting and orienting network scores and other standardized tests of attention. Likewise, comparisons between the ANT and an assessment based on TVA also yielded no significant correlations (Habekost et al., 2014). Whether this lack of correlation attests to the unique measurement properties of the ANT, or its lack of validity is unknown at this point.

Thus, to extend this tri-partite neurocognitive approach and to provide multiple yet integrated measures that can be compared across networks, we developed the Dalhousie Computerized Attention Battery (DalCAB; Butler et al., 2010; Eskes et al., 2013; Rubinfeld et al., 2014; Jones et al., 2015). The DalCAB is a battery of eight computerized reaction time tests, each test previously used individually in cognitive neuroscience research to measure multiple attentional functions within the vigilance, orienting and executive control attention networks. These tasks reflect concepts of attentional functions frequently studied in 
normal populations as well as in those affected by psychiatric or neurological disease/injury but, to date, have never been combined and integrated using standardized stimuli ${ }^{1}$ in a single, computerized battery.

The DalCAB includes the following tasks: simple and choice reaction time tasks to measure vigilance, a visual search task to measure orienting, and go/no-go, dual task, flanker, item working memory, and location working memory ${ }^{2}$ tasks to target executive control functions. The DalCAB emphasizes reaction time and accuracy measures that have been consistently related to attentional functions and can be sensitively and robustly measured (e.g., Sternberg, 1966; Wicklegren, 1977; see below). A description of all DalCAB tasks, the effects of interest within each task and literature relevant to each task are presented in Table $\mathbf{1 .}$ We have omitted the description of the location working memory task in the section below ${ }^{2}$.

\section{Simple Reaction Time (SRT, Vigilance)}

SRT is used to measure response readiness and motor reaction time (RT) to the onset of all stimuli presented. Previous research has indicated that the SRT task involves attention-demanding pre-trial vigilance (for stimulus onset and/or response initiation), and performance is affected by transient warning signals and tonic arousal changes (Petersen and Posner, 2012; Steinborn and Langner, 2012). In addition, if the interval between stimuli is varied, faster RTs are observed with longer response-stimulus intervals (RSIs), a phenomenon called the temporal preparation effect or fore-period effect (Vallesi et al., 2013). SRT is slowed in normal aging and in patients with frontal lobe alertness deficits (Godefroy et al., 2002, 2010). When the RSI is variable, older participants have shown a reversal in the fore-period effect related to decreased right prefrontal activation (Vallesi et al., 2009). SRT is also differentially slowed by dividing attention and by neurological disorders such as Parkinson's disease that affect frontal systems function (c.f. Henderson and Dittrich, 1998 for a full review).

\section{Go/No-Go (GNG, Executive Control)}

Frequently used to measure response inhibition or sustained attention, the GNG task employs a continuous stream of two different stimuli for which a binary decision must be made, such that one stimulus type requires a response (go) and the other stimulus type requires the participant to withhold a response (no-go). Response inhibition performance is measured by the percent of responses on no-go trials (false alarms; commission errors), particularly when go trials are more frequent than nogo trials (Carter et al., 2013). In contrast, sustained attention is measured by response performance on go trials (omission errors and reaction time), particularly when go trials are less frequent compared to no-go trials (also referred to as a vigilance or traditionally formatted task or TFT; Carter et al., 2013). Response inhibition deficits are seen in acquired brain injury, bipolar

\footnotetext{
${ }^{1}$ All tasks contained within the DalCAB employ a variation of playing cards or card suit stimuli, permitting direct comparison of performance across increasingly complex tasks. See (Figure 1).

${ }^{2}$ Due to methodological changes that resulted in a small sample size $(n=15)$, analysis of the location working memory task is not included in the current paper.
}

disorder, Parkinson's disease, and other neurological disorders (e.g., Claros-Salinas et al., 2010; Dimoska-Di Marco et al., 2011; Fleck et al., 2011). While sustained attention or vigilance decrements have frequently been studied in sleep disordered breathing (Kim et al., 2007), they have also been shown in Parkinson's disease (Hart et al., 1998).

\section{2-Choice Reaction Time (CRT, Vigilance)}

Often used to measure decision time and response selection, the CRT task requires different responses for each of two different stimuli presented in a continuous stream (e.g., left button for red stimuli, right button for black stimuli). Errors, reaction time decrements over time and switch costs, calculated as the difference in reaction time between trials that require a switch in response category (switch trials) vs. non-switch trials, are often used to determine deficits in decision and response selection time. CRT responses are slowed in dementia, stroke, multiple sclerosis, and other neurological disorders (e.g., Bailon et al., 2010; Stoquart-Elsankari et al., 2010).

\section{Dual Task (Executive Control)}

Often used to measure attentional control, attentional load effects, and interference, dual-task paradigms require the participant to perform two tasks simultaneously. By comparing the dual task performance to single task performance the degree of dysfunction related to attentional load or interference by the secondary task (i.e., dual task cost) can be measured (Baddeley and Della Sala, 1996). In dual task studies, addition of a concurrent secondary task greatly reduces primary task performance in many neurological disorders, including Alzheimer's disease, traumatic brain injury, and Parkinson's disease (Dalrymple-Alford et al., 1994; Della Sala et al., 1995, 2010).

\section{Flanker (Executive Control)}

The flanker task is used as a measure of selective attention, filtering, and/or conflict resolution and performance is considered to reflect the executive attention network. In this task a central target stimulus is presented with flanking stimuli (flankers) on two sides that are either the same as (congruent) or different than (incongruent) the central target stimulus. The participant must make a decision and response regarding a feature of the central stimulus (e.g., red or black) while ignoring/filtering the flanking stimuli. In healthy adults, reaction times are slowed and accuracy is lower on trials in which the flankers are incongruent with the target compared to when the flankers are congruent with the target (i.e., the reaction time interference effect), although the effect diminishes with practice (Ishigami and Klein, 2010, 2011). The RT interference effect has also been noted to increase with increasing age (Salthouse, 2010), although accuracy effects in older adults have been shown to be smaller than those of younger adults (D'Aloisio and Klein, 1990), suggesting that the larger RT interference effects in older adults are related to a response bias favoring accuracy over speed on incongruent trials. In patient groups, larger RT interference effects (i.e., impaired conflict resolution) have 
TABLE 1 | DaICAB task descriptions, outcome measures, and task-related variables and effects of interest.

\begin{tabular}{|c|c|c|c|c|}
\hline Task and description & $\begin{array}{l}\text { Outcome } \\
\text { measures }\end{array}$ & Task variable & Effect of interest & $\begin{array}{l}\text { Effect } \\
\text { obtained }\end{array}$ \\
\hline $\begin{array}{l}\text { SRT: Respond to each stimulus, with } \\
\text { varying response-stimulus intervals. }\end{array}$ & $\begin{array}{l}\mathrm{RT}^{\mathrm{b}} \\
\% \text { correct }\end{array}$ & $\begin{array}{l}\text { Response-stimulus interval (three, } \\
\text { between } 500 \text { and } 1500 \text { ms). }\end{array}$ & $\begin{array}{l}\text { Temporal preparation effect: Faster RTs with } \\
\text { longer RSIs (e.g., Henderson and Dittrich, } \\
\text { 1998; Vallesi et al., } 2013 \text { for review). }\end{array}$ & Yes \\
\hline
\end{tabular}

GNG: Respond to single target color, with high (80\%) or low (20\%) frequency targets.

$\mathrm{RT}^{\mathrm{b}}$
$\%$ correct

Response inhibition: Faster RTs and more false alarms (button press on a no-go trial) when go frequency is high (80\%).

Sustained attention: More omissions when go response is low (20\%; e.g., Carter et al., 2013).

CRT: Indicate the color of each stimulus (2-choice responses; 50\% each choice).

$\begin{array}{ll}\mathrm{RT}^{\mathrm{b}} & \text { Trial type (switch, no-switch in } \\ \% \text { correct } & \text { response). }\end{array}$
response). a change in response from the previous trial (e.g., Bailon et al., 2010).
Yes

Switch effect: Slower RTs on trials that require Yes

$\mathrm{RT}^{\mathrm{b}}(\mathrm{CRT}) \quad \mathrm{CRT}$ trial type (switch, no-switch);
$\%$ correct CRT Counting set size $(8,12)$ $\%$ correct counting
Switch effect in the CRT task: Slower RTs on trials that require a change in response from the previous trial.
Dual Task: Complete CRT while silently counting the number of each color of stimuli presented. Count probe for one color at the end of each set.
Working memory load effect: Slower choice RTs overall when compared to the single task CRT (Baddeley and Della Sala, 1996; Hommel and Doeller, 2005).

\begin{tabular}{|c|c|c|}
\hline $\begin{array}{l}\text { Flanker: Indicate shape of a central } \\
\text { target flanked above and below by } \\
\text { same- or different-shaped distractors } \\
\text { (50\% congruent with flanker shapes). }\end{array}$ & $\begin{array}{l}\mathrm{RT}^{\mathrm{b}} \\
\% \text { correct }\end{array}$ & $\begin{array}{l}\text { Flanker Congruency } \\
\text { (Congruent, Incongruent). }\end{array}$ \\
\hline IM: Indicate whether a probe item was & $\mathrm{RT}^{\mathrm{b}}$ & Set size (three, between 2 and 6); \\
\hline $\begin{array}{l}\text { present or absent in a preceding study } \\
\text { set of } 2-6 \text { items ( } 50 \% \text { present). }\end{array}$ & $\%$ correct & Trial type (present, absent). \\
\hline
\end{tabular}

Congruency effect: Slower RTs and more errors when flanking stimuli do not match the target (incongruent trials; Eriksen and Eriksen, 1974; Ishigami and Klein, 2010, 2011).

Set size effect: Slower RTs for larger set sizes (Sternberg, 1969; Poewe et al., 1991; Ferraro and Balota, 1999).

el

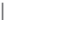

Yes

Yes

Set size effect: Slower RTs for larger set sizes (Sternberg, 1969; Poewe et al., 1991; Ferraro and Balota, 1999); ${ }^{1}$

Set size (three, between 2 and 6);

Trial type (present, absent).

\begin{tabular}{llll}
\hline vS: Locate and indicate orientation & $\mathrm{RT}^{\mathrm{b}}$ & Set size (three, between 6 and 18); & Set size effect: Slower RTs for larger set sizes in $\quad$ Yes \\
(upright vs. inverted; $50 \%$ each) of a & $\%$ correct & Search type (feature, conjunction). & conjunction search (Treisman and Gelade, \\
target among different shape & & 1980; Davis and Palmer, 2004).
\end{tabular}

distractors that are a different color

(feature search) or the same color

(conjunction search) as the target.

${ }^{b}$ Reaction time derived from correct trials only.

been associated with elevated symptom severity in adults with post-traumatic stress disorder (Leskin and White, 2007) and borderline personality disorder (Posner et al., 2002). In addition, while interference effects are significantly large in dementia patients (Fernandez-Duque and Black, 2006; Krueger et al., 2009), across many neurodegenerative diseases, accuracy and reaction time performances on the flanker task are associated with different patterns of regional brain atrophy (Luks et al., 2010).

\section{Item Working Memory (Executive Control)}

Used to measure working memory capacity and scanning efficiency, the item working memory task presents a set of stimuli to be remembered. This stimulus set is followed after a delay by a probe stimulus. The participants' task is to indicate whether the probe stimulus was present in the previously viewed set. In healthy individuals, as the number of items in the set increases, decision accuracy decreases, and the time required to make a determination about the probe stimulus increases (Sternberg, 1969). In normal aging, memory scanning slows as evidenced by increases in slope and intercept on this task (i.e., the increase in reaction time for each additional item in the set, representing memory scanning rate, and the point at which the set size regression line crosses the $y$-axis, representing the speed of combined encoding, decision making and response selection aspects of the task), and these measures increase further in 
individuals with dementia (Ferraro and Balota, 1999). Compared to healthy controls, patterns of memory scanning speed and decision accuracy differ depending on the neurological disorder and the medication state studied. For example, patients with multiple sclerosis are equally accurate but have slower memory scanning speed (Janculjak et al., 1999), while Parkinson's patients are less accurate and have "normal" memory scanning speed unless they are on medication (levodopa; Poewe et al., 1991). A description of the location working memory task can be found in Table 1, but will not be discussed here.

\section{Visual Search (Orienting and Selection)}

The visual search task has been used to measure spatial orienting and selection. In this task, a target is presented within distractor sets of various sizes and the participant's task is to respond to the target (either a detection or identification response; Davis and Palmer, 2004). When the target stimulus is very different from the distractors (e.g., a different color) response to the target is fast and independent of the number of distractors (feature search). In contrast, if the target and distractors share some (but not all) features in common with the target, search is slower and influenced by distractor set size (conjunction search; Treisman and Gelade, 1980). Compared to healthy controls, a differential effect of performance has been found across feature and conjunction search types depending on the neurological disorder. For example, overall performance on both search types has been shown to decrease (i.e., increased RTs and error rates) in persons with mild cognitive impairment (e.g., Tales et al., 2005) and Alzheimer's Disease (e.g., Foster et al., 1999; Tales et al., 2005). In contrast, while persons with Schizophrenia have been shown to exhibit slowed RTs in conjunction search, little difference is found between patients and controls for feature search. Computerized visual search paradigms have also been shown to differentiate between stroke patients and healthy controls and between stroke patients with and without spatial neglect.

The purpose of this study is twofold. First, we report normative data for seven of the DalCAB tasks ${ }^{2}$ obtained from a preliminary sample of healthy adults $(n=100,18-31$ years of age), including analyses of individual tasks to determine the presence or absence of the expected pattern of effects within each task. These data are intended to serve as pilot evidence for further exploration of the convergent validity of our interpretation of the $\mathrm{DalCAB}^{3}$, Second, we report the test-retest reliability and practice effects from our healthy adult sample $(n=96)$.

\section{METHODS}

\section{Participants}

One-hundred and three healthy adults were enrolled in the study. Demographic information for participants included in the analyses is presented in Table 2. Participants were recruited

\footnotetext{
${ }^{3} \mathrm{We}$ have indirectly compared the pattern of results/performance on the DalCAB to those reported by others using similar tasks purported to measure the components of attention as an initial step in exploring the validity of our interpretation of the DalCAB. Formal evidence of the validity of our interpretation of the DalCAB is needed before conclusions about our results can be generalized.
}

TABLE 2 | Participant demographic information for healthy adults completing the DaICAB at the baseline and 24-h testing sessions.

\begin{tabular}{lcc}
\hline & Baseline & $\mathbf{2 4 - h}$ \\
\hline $\mathrm{N}$ & 100 & 96 \\
Mean age (SD) & $21.8(3.1)$ years & $21.7(3.1)$ years \\
Number female (\%) & $64(64 \%)$ & $60(62.5 \%)$ \\
Number right-handed (\%) & $92(92 \%)$ & $87(90.6 \%)$ \\
Mean education (SD) & $14.8(2.4)$ years & $14.8(2.4)$ years
\end{tabular}

through an undergraduate research participant pool at Dalhousie University in exchange for partial course credit or through the use of flyers and notices posted in and around the Dalhousie University community (e.g., library, coffee shops, etc.) in exchange for a per-session dollar amount. All participants provided informed consent following procedures approved by the Capital District Health Authority Research Ethics Board in Halifax, Nova Scotia, Canada. In advance of participation, all participants were screened through self-report for past or current neurological disorders, loss of consciousness for more than $5 \mathrm{~min}$, history of neuropsychiatric disorders and current use of antidepressant or anti-anxiolytic medications known to influence cognitive performance. Two participants were excluded in advance of participation due to their medication use and data from one participant were removed from analysis due to the use of an incorrect testing procedure. Four participants also withdrew or were removed after the baseline session due to noncompliance with the study protocol. Thus, 100 participants completed the DalCAB at baseline and 96 completed the DalCAB at $24 \mathrm{~h}$ after baseline (see Table 2 for sample demographic information).

\section{Apparatus and Procedure}

All tasks contained within the DalCAB employ a variation of playing cards or card suit stimuli (example stimuli shown in Figure 1). Stimuli were presented on Apple Computers (iMac G3 and iMac with a 27-inch monitor). Participants' responses to stimuli were collected using a two-button mouse. Participants were seated $50 \mathrm{~cm}$ away from the computer monitor on which all instructions, practice trials, and experimental trials for the DalCAB tasks were presented. For each task, the experimenter read the instructions printed on the screen to the participant. Speed and accuracy were equally emphasized in all task instructions. Participants were then given the opportunity to practice the task (12-36 trials, depending on the task) during which time they received auditory and/or visual feedback about their performance. Once comfortable with the nature of the task, the participant completed the experimental trials without auditory or visual feedback about their performance. All participants completed the DalCAB tasks in the same order (as described above). Programming changes during the development of the Location working memory task resulted in a small sample size $(n=15)$; thus, the Location working memory task will not be presented in this report ${ }^{2}$. A description of all tasks included in the DalCAB are presented in Table 1 (see also Jones et al., 2015). 
A

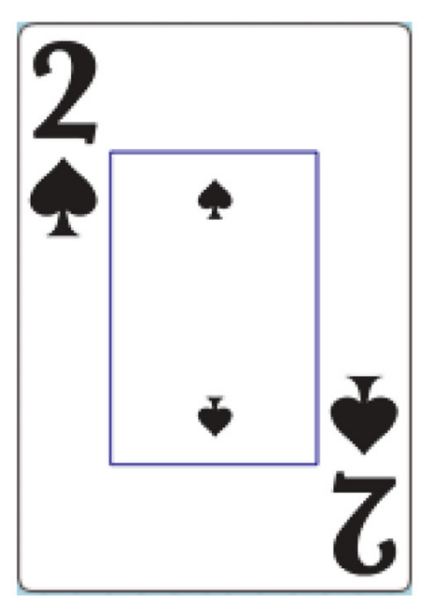

B

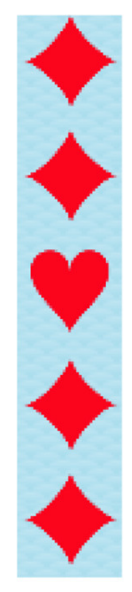

FIGURE 1 | Example of card suit stimuli used in the DalCAB tasks. (A) Card as shown in simple response, inhibition, decision speed, dual task and item working memory tasks. (B) Card suit shapes as shown in the flanker tasks. Card suit shapes like those in (B) are also used in the visual search task.

Each DalCAB session, including practice and experimental trials, took $\sim 1$-h to complete.

\section{DATA ANALYSIS}

Mean reaction time (RT) in milliseconds and accuracy measures (\% correct, \% false alarms) were collected. Reaction times less than $100 \mathrm{~ms}$ were coded as anticipatory and were excluded from analysis. Reaction times greater than the maximum reaction time (varied by task) were coded as misses and were also excluded from analysis [mean percent anticipations across tasks (SD) $=$ $0.41 \%(0.74 \%)$; mean percent misses across tasks $(\mathrm{SD})=1.2 \%$ (2\%)]. All correct trials with RTs between these lower and upper bounds were included in RT analyses. No further data cleaning or transformations of the data were applied prior to analysis ${ }^{4}$. For all analyses, the alpha level required for significance was set at $p=0.05$ and, where appropriate, pairwise comparisons with Bonferroni correction were used to explore significant main

${ }^{4}$ The average skewness value across the analyzed DalCAB tasks presented here was 2.24 (range: 1.53-3.15). A previous analysis of these data in which more conservative lower and upper bound RT cutoffs were employed as a data cleaning method was carried out. Lower bound RT cutoff values were defined as the minimum reaction time at which $75 \%$ accuracy was achieved on each individual task, and ranged from 100 to $400 \mathrm{~ms}$ depending on task complexity (see Christie et al., 2013). Below these lower bound cutoffs, responses were considered anticipations and were excluded from analysis. Upper bound RT outliers on each task were defined within each participant using a $z$-score cut-off value of 3.29 (Tabachnick et al., 2001, pp. 67). Analysis of these cleaned data resulted in no change to the pattern of results or the assessments of test-retest reliability reported here. We also analyzed the data after applying an inverse transformation (i.e., 1/RT). Analysis of these transformed data was consistent with the analyses reported here with the following three exceptions: (1) a significant main effect of session in the SRT task (consistent with our already reported practice effect); (2) A significant interaction between gender and RSI in the SRT task; post hoc analyses revealed the same pattern of RT across RSI for both males and females, consistent with the pattern of RT across RSI reported above and; (3) longer RTs for females than males in the feature search task. No changes in the assessment of practice effects or test-retest reliability were found using the transformed data. effects and interactions. Greenhouse-Geisser corrected $p$-values are reported.

\section{Individual Task Analyses: Mean Reaction Time and Accuracy}

Table 3 presents mean reaction times and standard deviation of reaction times of performance for male and female participants on each level of the independent variables of interest for all tasks at the baseline and 24-h sessions. For each task, we analyzed task specific effects on reaction time across sessions using a series of mixed factor Analysis of Variance (ANOVAs), with a betweensubjects factor of Sex (male, female) and within-subjects factors of Session (baseline, 24-h), and other independent variables related to the individual tests (described in Table 1). Only relevant task effects for reaction time are presented in text (below), but all main and interaction effect results for reaction time are presented in Table 3.

Table 4 presents mean accuracy and standard deviation of accuracy of performance for male and female participants on each level of the independent variables of interest for all tasks at the baseline and 24-h sessions. With the exception of the choice reaction time component of the dual task (described below) and the go-no-go task, a comparison of the pattern of mean RTs and accuracy within each task revealed no apparent speedaccuracy trade-offs. Given that the DalCAB was designed to assess attentional functioning using predominantly RT measures, and accuracy was high in our young, healthy adult sample (see Table 4), we have only presented analysis of accuracy data for a few relevant measures below (percent false alarms in the Go/NoGo task and percent correct in the item work memory task). All main and interaction effects on accuracy in the Go/No-Go and item working memory tasks are presented in Table 4 . Standard error of the mean (SE) of RT and accuracy data are provided in the text where appropriate.

\section{Individual Task Performance Analyses: Practice Effects}

To quantify the change in reaction time across the repeated testing sessions, mean practice effects (24-h mean-baseline mean) for overall mean RT and mean RT across the levels of the DalCAB task variables of interest are presented in Table 5. Differences in reaction times between baseline and the 24-h session were assessed using paired samples $t$-tests. Standard deviation of the difference scores in performance and effect sizes for practice effects (Cohen's d) were also calculated for the session 24-h after baseline. These values are also shown in Table 5. The ICC scores, practice effects, standard deviation of the difference score, and effect sizes can be used to compute reliable change indices.

\section{Individual Task Performance Analysis: Test-Retest Reliability}

The test-retest reliability of performance as defined by the dependent variables in each task was analyzed using intra-class correlations (ICC) comparing the 24-h session data to baseline. ICC are presented in Table 5. For the current analysis, intraclass 
TABLE 3 | Reaction times (RT; in ms) for relevant variables on the DalCAB tasks for groups of male and female participants at the baseline and 24-h testing sessions.

\begin{tabular}{|c|c|c|c|c|c|c|}
\hline \multirow[t]{2}{*}{ DalCAB Task variable ${ }^{*}$} & \multicolumn{2}{|c|}{ Male } & \multicolumn{2}{|c|}{ Female } & \multirow[t]{2}{*}{ Main effects } & \multirow[t]{2}{*}{ Interactions } \\
\hline & $\begin{array}{c}\text { Baseline } \\
\text { Mean (SD) }\end{array}$ & $\begin{array}{c}\text { 24-h } \\
\text { Mean (SD) }\end{array}$ & $\begin{array}{c}\text { Baseline } \\
\text { Mean (SD) }\end{array}$ & $\begin{array}{c}\text { 24-h } \\
\text { Mean (SD) }\end{array}$ & & \\
\hline
\end{tabular}

\begin{tabular}{|c|c|c|c|c|c|}
\hline \multicolumn{6}{|l|}{ SRT } \\
\hline $\mathrm{N}$ & 36 & 35 & 64 & 60 & RSI: $F_{(2,186)}=206.88, p<.001$ \\
\hline Mean RT & $252(31)$ & $255(38)$ & $274(61)$ & $265(42)$ & Session: $F_{(1,93)}<1, p=0.745$ \\
\hline $500 \mathrm{~ms} \mathrm{RSI}^{\mathrm{a}}$ & $282(44)$ & $288(47)$ & $300(72)$ & $296(59)$ & Sex: $F_{(1,93)}=3.14, p=0.07$ \\
\hline $1000 \mathrm{~ms} \mathrm{RSI}^{\mathrm{a}}$ & 239 (32) & $242(48)$ & $264(60)$ & $251(39)$ & \\
\hline$\left.1500 \mathrm{~ms} R S\right|^{\mathrm{a}}$ & $234(28)$ & $236(28)$ & $259(57)$ & $249(36)$ & \\
\hline Preparation effect ${ }^{b}$ & $-47(31)$ & $-52(39)$ & $-41(34)$ & $-48(35)$ & \\
\hline \multicolumn{6}{|l|}{ GNG } \\
\hline $\mathrm{N}$ & 36 & 35 & 64 & 61 & Percent-Go-trials: \\
\hline Mean RT: 20\% Go & $361(72)$ & $366(90)$ & $378(83)$ & $370(82)$ & $F_{(1,94)}=269.13, p<0.001$ \\
\hline Mean RT: 80\% Go & $318(74)$ & $309(79)$ & $332(82)$ & $318(87)$ & $\begin{array}{l}\text { Session: } F_{(1,94)}=1.21, p=0.27 \\
\text { Sex: } F_{(1,94)}=1.70, p=0.19\end{array}$ \\
\hline
\end{tabular}

$\mathrm{RSI} \times$ Session: $F_{(2,186)}=1.58, p=0.209$ $\mathrm{RSI} \times$ Sex: $F_{(2,186)}<1, p=0.529$

Session $\times$ Sex: $F_{(1,94)}=2.27, p=0.135$ $\mathrm{RSI} \times$ Session $\times$ Sex: $F_{(2,186)}<1, p=0.673$

(

\begin{tabular}{|c|c|c|c|c|c|c|}
\hline \multirow{2}{*}{\multicolumn{7}{|c|}{ CRT }} \\
\hline & & & & & & \\
\hline $\begin{array}{l}\text { N } \\
\text { Mean RT } \\
\text { No Switch } \\
\text { Switch } \\
\text { Switch Cost }\end{array}$ & $\begin{array}{c}36 \\
423(130) \\
412(71) \\
445(64) \\
34(42)\end{array}$ & $\begin{array}{c}35 \\
397(121) \\
383(57) \\
417(52) \\
33(32)\end{array}$ & $\begin{array}{c}64 \\
435(125) \\
420(57) \\
449(57) \\
29(32)\end{array}$ & $\begin{array}{c}61 \\
409(117) \\
393(53) \\
426(63) \\
33(33)\end{array}$ & $\begin{array}{l}\text { Trial type: } \boldsymbol{F}_{(\mathbf{1}, 94)}=\mathbf{1 0 8 . 3 4} \\
\boldsymbol{p}<\mathbf{0 . 0 0 1} \\
\text { Session: } \boldsymbol{F}_{(\mathbf{1}, 94)}=\mathbf{2 3 . 9 4} \\
\boldsymbol{p}<\mathbf{0 . 0 0 1} \\
\text { Sex: } F_{(1,94)}<1, p=0.45\end{array}$ & $\begin{array}{l}\text { Trial type } \times \text { Session: } F_{(1,94)}<1, p=0.6 \\
\text { Trial type } \times \text { Sex: } F_{(1,94)}<1, p=0.607 \\
\text { Session } \times \text { Sex: } F_{(1,94)}<1, p=0.76 \\
\text { Trial type } \times \text { Session } \times \operatorname{Sex:~} F_{(1,94)}<1 \\
p=0.503\end{array}$ \\
\hline \multicolumn{7}{|l|}{ DUAL TASK CRT } \\
\hline $\begin{array}{l}\text { N } \\
\text { Mean RT } \\
\text { No Switch } \\
\text { Switch } \\
\text { Switch Cost } \\
\text { WM load effect }\end{array}$ & $\begin{array}{c}36 \\
529(87) \\
463(81) \\
610(102) \\
146(54) \\
101(88)\end{array}$ & $\begin{array}{c}29 \\
482(75) \\
419(69) \\
560(92) \\
141(50) \\
85(55)\end{array}$ & $\begin{array}{c}64 \\
534(90) \\
464(72) \\
619(115) \\
155(67) \\
99(63)\end{array}$ & $\begin{array}{c}59 \\
473(68) \\
410(54) \\
550(87) \\
140(54) \\
65(61)\end{array}$ & $\begin{array}{l}\text { Trial type: } \boldsymbol{F}_{(\mathbf{1}, \mathbf{8 6})}=\mathbf{5 8 3 . 1 6} \\
\boldsymbol{p}<0.001 \\
\text { Session: } \boldsymbol{F}_{(\mathbf{1}, 86)}=\mathbf{6 4 . 3 3} \\
\boldsymbol{p}<0.001 \\
\text { Sex: } F_{(1,86)}<1, p=0.89\end{array}$ & $\begin{array}{l}\text { Trial type } \times \text { Session: } F_{(1,} \\
\text { Trial type } \times \text { Sex: } F_{(1,86)} \\
\text { Session } \times \text { Sex: } F_{(1,86)}= \\
\text { Trial type } \times \text { Session } \times \text { Se) } \\
F_{(1,86)}=1.16, p=0.28\end{array}$ \\
\hline \multicolumn{7}{|l|}{ FLANKER } \\
\hline $\begin{array}{l}\mathrm{N} \\
\text { Mean RT } \\
\text { Congruent } \\
\text { Incongruent } \\
\text { Interference effect }^{\mathrm{e}}\end{array}$ & $\begin{array}{c}36 \\
455(107) \\
445(48) \\
464(47) \\
19(24)\end{array}$ & $\begin{array}{c}35 \\
444(118) \\
435(54) \\
453(48) \\
18(22)\end{array}$ & $\begin{array}{c}63 \\
484(122) \\
476(59) \\
492(57) \\
16(20)\end{array}$ & $\begin{array}{c}61 \\
468(122) \\
459(65) \\
475(61) \\
16(19)\end{array}$ & $\begin{array}{l}F C g: F_{(1,94)}=105.11, p<0.001 \\
\text { Session: } F_{(1,94)}=9.61 \\
p=0.003 \\
\text { Sex: } F_{(1,94)}=6.29, p=0.014\end{array}$ & $\begin{array}{l}\text { FCg } \times \text { Session: } F_{(1,94)}<1, p=0.784 \\
\text { FCg } \times \text { Sex: } F_{(1,94)}<1, p=0.501 \\
\text { Session } \times \text { Sex: } F_{(1,94)}=1.15, p=0.28 \\
\text { FCg } \times \text { Session } \times \text { Sex: } F_{(1,94)}<1, p=0.783\end{array}$ \\
\hline \multicolumn{7}{|c|}{ ITEM WORKING MEMORY } \\
\hline $\begin{array}{l}\text { N } \\
\text { Mean RT } \\
\text { Set size: } 2 \\
\text { Set size: } 4 \\
\text { Set size: } 6 \\
\text { Set-size slope }\end{array}$ & $\begin{array}{c}23 \\
828(286) \\
726(136) \\
852(126) \\
937(166) \\
113(61)\end{array}$ & $\begin{array}{c}23 \\
788(284) \\
666(96) \\
813(147) \\
892(185) \\
117(70)\end{array}$ & $\begin{array}{c}43 \\
830(247) \\
731(98) \\
860(117) \\
929(117) \\
103(39)\end{array}$ & $\begin{array}{c}42 \\
765(241) \\
682(106) \\
793(104) \\
852(133) \\
84(44)\end{array}$ & $\begin{array}{l}\text { Set size: } \boldsymbol{F}_{(\mathbf{2}, \mathbf{1 2 6})}=\mathbf{2 2 0 . 2 4} \\
\boldsymbol{p}<\mathbf{0 . 0 0 1} \\
\text { Target: } F_{(1,63)}=1.93, p=0.169 \\
\text { Session: } \boldsymbol{F}_{(\mathbf{1}, \mathbf{6 3})}=\mathbf{2 7 . 7 2} \\
\boldsymbol{p}<\mathbf{0 . 0 0 1} \\
\text { Sex: } F_{(1,63)}<1, p=0.789\end{array}$ & 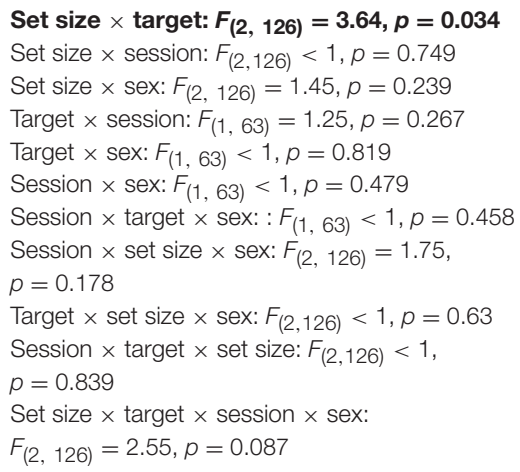 \\
\hline
\end{tabular}
Percent-Go-trials $\times$ Session: $\boldsymbol{F}_{(1,94)}=\mathbf{9 . 2 3}$,
$\boldsymbol{p}=\mathbf{0 . 0 0 3}$

Percent-Go-trials $\times$ Sex: $F_{(1,94)}<1, p=0.67$ Session $\times$ Sex: $F_{(1,94)}=2.43, p=0.122$ Percent-Go-trials $\times$ Session $\times$ Sex: $F_{(1,94)}<1$, $p=0.465$

\section{VISUAL SEARCH}

$$
36
$$

35

64

61

\section{Feature Search}

Mean RT

Set size: 6

Set size: 12

Set size: 18

Set-size slope ${ }^{f}$

$624(178)$

616 (63)

$631(78)$

$625(70)$

$<1$ (3)
593 (181) 584 (65) 591 (69) 602 (72)

2 (2)
660 (238) 649 (93) $667(140)$ 665 (140) 1 (6.0)
621 (229) Set size: $\boldsymbol{F}_{(\mathbf{2}, \mathbf{1 8 8})}=\mathbf{7 . 4 6}$, 613 (84) $\quad \boldsymbol{p}<\mathbf{0 . 0 0 1}$ 619 (81) Session: $\boldsymbol{F}_{(\mathbf{1}, \mathbf{9 4})}=\mathbf{1 7 . 4 4}$, 630 (112) $\boldsymbol{p}<\mathbf{0 . 0 0 1}$ $1(5.3)$
Set size $\times$ Session: $F_{(2,188)}=2.00, p=0.138$ Set size $\times$ Sex: $F_{(2,188)}<1, p=0.859$ Session $\times$ Sex: $F_{(1,94)}<1, p=0.487$ Set size $\times$ Session $\times$ Sex: $F_{(2,188)}<1$, $p=0.818$ 
TABLE 3 | Continued

\begin{tabular}{|c|c|c|c|c|c|c|}
\hline DalCAB Task variable ${ }^{*}$ & \multicolumn{2}{|c|}{ Male } & \multicolumn{2}{|c|}{ Female } & Main effects & Interactions \\
\hline \multicolumn{7}{|l|}{ Conjunction Search } \\
\hline $\begin{array}{l}\text { Mean } R T \\
\text { Set size: } 6 \\
\text { Set size: } 12 \\
\text { Set size: } 18 \\
\text { Set size slope }\end{array}$ & $\begin{array}{l}1319(783) \\
1006(138) \\
1328(220) \\
1613(335) \\
51(23)\end{array}$ & $\begin{array}{c}1123(575) \\
884(123) \\
1123(150) \\
1352(160) \\
39(11)\end{array}$ & $\begin{array}{l}1281(677) \\
1007(188) \\
1281(229) \\
1557(305) \\
46(19)\end{array}$ & $\begin{array}{l}1139(594) \\
912(148) \\
1130(212) \\
1368(276) \\
38(14)\end{array}$ & $\begin{array}{l}\text { Set size: } F_{(2,188)}=639.02 \\
p<0.001 \\
\text { Session: } F_{(1,94)}=\mathbf{1 2 8 . 6 8} \\
p<0.001 \\
\text { Sex: } F_{(1,94)}<1, p=0.857\end{array}$ & $\begin{array}{l}\text { Set size } \times \text { Session: } \boldsymbol{F}_{\mathbf{( 2 ,}, \mathbf{1 8 8})}=\mathbf{1 3 . 7 7}, \\
\boldsymbol{p}<\mathbf{0 . 0 0 1} \\
\text { Set size } \times \text { Sex: } F_{(2,188)}<1, p=0.357 \\
\text { Session } \times \text { Sex: } F_{(1,94)}=2.65, p=0.107 \\
\text { Set size } \times \text { Session } \times \text { Sex: } F_{(2,188)}<1, \\
p=0.536\end{array}$ \\
\hline
\end{tabular}

*Please refer to written results section for a description of the effects of DalCAB task variables on mean reaction time.

${ }^{a}$ Response-stimulus interval.

${ }^{b}$ Preparation effect $=1500-500 \mathrm{~ms}$ RSI mean RT.

${ }^{c}$ Switch cost $=$ mean RT switch trials - mean RT non-switch trials.

${ }^{d}$ Working memory load effect $=$ dual task mean RT - CRT mean RT.

eInterference effect = incongruent mean RT - congruent mean RT.

${ }^{f}$ Slope units $=$ ms/item.

g Flanker congruency.

Bold indicates significance at the $p<0.05$.

correlations at or above 0.700 were considered "Good," 0.800 or higher were considered "Very Good" and 0.900 or higher were considered "Excellent” (Dikmen et al., 1999; Van Ness et al., 2008; Chen et al., 2009).

\section{RESULTS}

Overall, the expected pattern of effects across the independent variables of interest within each task were found (as described in Table 1) and the majority of the ICCs (11 of 19) were greater than 0.700 (i.e., at least Good reliability). A specific description of these results within each task is presented below.

\section{Simple Reaction Time (SRT)}

One female participant was removed from the SRT task analysis due to an extremely low percentage of correct responses in the 24 -h session $(61 \%$ missed trials, i.e., RTs $>1500 \mathrm{~ms})$. The mixed factor ANOVA on mean reaction time (as described above), including the task variable of RSI, revealed the anticipated preparation effect; i.e., faster responses at longer RSIs $\left[\mathrm{M}_{\mathrm{RT}} \pm \mathrm{SE}\right.$ $\mathrm{RSI} 500=290.48 \pm 5.65>\mathrm{M}_{\mathrm{RT}} \pm \mathrm{SE}$ RSI1000 $=247.77 \pm 4.31$ $(p<0.001)>\mathrm{M}_{\mathrm{RT}} \pm \mathrm{SE} \operatorname{RSI} 1500=243.60 \pm 3.92(p=0.04) ;$ $F_{(2,186)}=206.88, M S E=792.39$, Table 3]. Twenty-four hour practice effects were not significant for the SRT task, for overall mean reaction time or the preparation effect (Table 5).

The test-retest reliability (ICC) score of mean RTs in the 24h session was Very Good (0.825). In contrast, ICC scores for the RT preparation effect ( $24 \mathrm{~h}$ session RT - baseline RT) were statistically significant but much lower, falling below the Good range (0.570).

\section{Go/No-Go (GNG)}

The mixed factor ANOVA on mean reaction time and accuracy (as described above) including the task variable of percent-Gotrials $(20 \%-\mathrm{Go}, 80 \%-\mathrm{Go})$ revealed the expected pattern of faster reaction times $\left[F_{(1,94)}=269.13, M S E=784.88, p<0.001\right]$ and more false alarms $\left[\mathrm{FA} ; F_{(1,94)}=129.93, M S E=0.005\right.$, $p<0.001$ ] in the $80 \%$-Go condition than the $20 \%$-Go condition at baseline and 24-h later (Tables 3, 4; there were no misses in the Go-no-go task). Practice effects for reaction times and false alarms were significant at 24 -h for the $80 \%$ Go-trial condition only (Table 5) and revealed a possible speed-accuracy tradeoff in the Go/No-Go task; participants responded faster and made more false alarms overall at 24-h compared to baseline $\left(\mathrm{M}_{\mathrm{RT}} \pm \mathrm{SE}\right.$ $24-\mathrm{h}=315.22 \pm 4.81, \mathrm{M}_{\mathrm{RT}} \pm \mathrm{SE}$ baseline $=324.94 \pm 4.17, p=$ $0.003 ; \mathrm{M}_{\mathrm{FA}} \pm \mathrm{SE} 24-\mathrm{h}=9.7 \pm 0.9 \%, \mathrm{M}_{\mathrm{FA}} \pm \mathrm{SE}$ baseline $=7.2 \pm$ $0.8 \%, p=0.011)$.

ICC scores of mean RTs for 20 and $80 \%-G o$ trials at the 24$\mathrm{h}$ session were in the Very Good range (24-h: 0.836 and 0.847, respectively). In contrast, the reliability score for the percent false alarms was below the Good range for both the 20 and $80 \%$ Go trial conditions at the 24-h interval (ICC $=0.252$ and 0.548 , respectively).

\section{2-Choice Reaction Time (CRT)}

The mixed factor ANOVA on mean reaction time (as described above), including the task variable of Trial Type (switch, nonswitch) revealed the expected pattern of switch costs; participants were slower to respond when the stimulus/response changed on consecutive trials (i.e., $\mathrm{M}_{\mathrm{RT}} \pm \mathrm{SE}$ switch trials $=432.9 \pm$ $5.6 \mathrm{~ms}$ ) than when the stimulus/response remained the same [i.e., $\mathrm{M}_{\mathrm{RT}} \pm \mathrm{SE}$ non-switch trials $=400.6 \pm 5.6 \mathrm{~ms} ; F_{(1,94)}=108.34, M S E$ $=857.65, p<0.001]$. A significant practice effect for mean RT was found indicating that participants were faster at 24-h than at baseline $\left(\mathrm{M}_{\mathrm{RT} 24-\mathrm{h} \pm \mathrm{SE}}=404.6 \pm 5.7 \mathrm{~ms}, \mathrm{M}_{\mathrm{RT}}\right.$ baseline $\pm \mathrm{SE}=$ $428.9 \pm 6.1 \mathrm{~ms}, p<0.001)$; no practice effects were found for the RT switch cost (Table 5).

The test-retest reliability score of mean RTs at the 24-h interval was in the Good range (24-h: 0.749), but the test-retest reliability score for the RT switch cost (i.e., RT Switch minus RT No-switch) was below the Good range (24-h: 0.609, Table 5). 
TABLE 4 | Mean accuracy for independent variables on the DalCAB tasks for groups of male and female participants at the baseline and 24-h testing sessions.

\begin{tabular}{|c|c|c|c|c|c|c|}
\hline \multirow{2}{*}{$\begin{array}{l}\text { DalCAB Task } \\
\text { variable* }^{*}\end{array}$} & \multicolumn{2}{|c|}{ Male } & \multicolumn{2}{|c|}{ Female } & \multirow[t]{2}{*}{ Main effects } & \multirow[t]{2}{*}{ Interactions } \\
\hline & $\begin{array}{c}\text { Baseline } \\
\text { Mean (SD) }\end{array}$ & $\begin{array}{c}24-h \\
\text { Mean (SD) }\end{array}$ & $\begin{array}{c}\text { Baseline } \\
\text { Mean (SD) }\end{array}$ & $\begin{array}{c}\text { 24-h } \\
\text { Mean (SD) }\end{array}$ & & \\
\hline \multicolumn{7}{|l|}{ SRT } \\
\hline $\mathrm{N}$ & 36 & 35 & 64 & 60 & & \\
\hline Mean \% correct & $98.1(2.4)$ & $95.8(4.6)$ & $98.8(1.5)$ & $97.9(2.2)$ & & \\
\hline $500 \mathrm{~ms} \mathrm{RSI}^{\mathrm{a}}$ & $99.9(0.1)$ & $98.9(4.6)$ & $99.8(4.5)$ & $99.7(2.0)$ & & \\
\hline 1000ms RSI ${ }^{\mathrm{a}}$ & $99.0(2.0)$ & $98.1(3.2)$ & $98.8(3.0)$ & $98.8(2.1)$ & & \\
\hline$\left.1500 \mathrm{~ms} R S\right|^{\mathrm{a}}$ & $95.6(6.6)$ & $90.4(8.6)$ & $97.7(3.7)$ & $95.3(5.3)$ & & \\
\hline \multicolumn{7}{|l|}{ GNG } \\
\hline $\begin{array}{l}\text { N } \\
20 \% \text { Go: } \% \\
\text { correct } \\
20 \% \text { Go: \% FAb } \\
80 \% \text { Go: \% } \\
\text { correct } \\
80 \% \text { Go: } \% \text { FA }^{b}\end{array}$ & $\begin{array}{c}36 \\
99.7(1.7) \\
0.3(0.6) \\
99.8(0.5) \\
8.1(9.3)\end{array}$ & $\begin{array}{c}35 \\
99.4(2.4) \\
0.3(0.7) \\
99.3(2.2) \\
8.9(6.8)\end{array}$ & $\begin{array}{c}64 \\
100(0) \\
0.3(0.6) \\
99.9(.3) \\
6.6(6.8)\end{array}$ & $\begin{array}{c}61 \\
99.5(2.2) \\
0.2(0.5) \\
99.8(1.2) \\
10.2(9.7)\end{array}$ & $\begin{array}{l}P C \\
\text { Percent go-trials: } F_{(1,94)}<1, \\
p=0.669 \\
\text { Session: } \boldsymbol{F}_{(\mathbf{1}, 94)}=\mathbf{5 . 1 9} \\
\boldsymbol{p}=\mathbf{0 . 0 2 5} \\
\text { Sex: } F_{(1,94)}=1.7, p=0.19 \\
F A \\
\text { Percent go-trials: } \\
\boldsymbol{F}_{(\mathbf{1}, \mathbf{9 4})}=\mathbf{1 2 9 . 9 3}, \boldsymbol{p}<\mathbf{0 . 0 0 1} \\
\text { Session: } \boldsymbol{F}_{(\mathbf{1}, 94)}=\mathbf{4 . 3 2}, \boldsymbol{p}=\mathbf{0 . 0 4} \\
\text { Sex: } F_{(1,94)}=1.10, p=0.29\end{array}$ & $\begin{array}{l}P C \\
\text { Percent-Go-trials } \times \text { Session: } F_{(1,94)}<1, \\
p=0.97 \\
\text { Percent-Go-trials } \times \text { Sex: } F_{(1,94)}<1, \\
p=0.77 \\
\text { Session } \times \text { Sex: } F_{(1,94)}<1, p=0.75 \\
\text { Percent-Go-trials } \times \text { Session } \times \text { Sex: } \\
F_{(1,94)}=2.87, p=0.093 \\
F A \\
\text { Percent-Go-trials } \times \text { Session: } \\
F_{(1,94)}=\mathbf{4 . 9 8 ,} \boldsymbol{p}=\mathbf{0 . 0 3 1} \\
\text { Percent-Go-trials } \times \text { Sex: } F_{(1,94)}<1, \\
p=0.986 \\
\text { Session } \times \text { Sex: } F_{(1,94)}<1, p=0.75 \\
\text { Percent-Go-trials } \times \text { Session } \times \text { Sex: } \\
F_{(1,94)}=2.0, p=0.16 F_{(1,94)}=2.0 \\
p=0.16\end{array}$ \\
\hline
\end{tabular}

\begin{tabular}{|c|c|c|c|c|c|c|}
\hline \multicolumn{7}{|l|}{ CRT } \\
\hline $\mathrm{N}$ & 36 & 35 & 64 & 61 & & \\
\hline Mean \% correct & $95.0(5.7)$ & $95.0(4.4)$ & $96.4(2.8)$ & $96.4(3.2)$ & & \\
\hline No Switch & $95.0(6.8)$ & $95.3(5.4)$ & 96.2 (3.3) & $96.3(4.1)$ & & \\
\hline Switch & $95.1(5.8)$ & $94.6(4.9)$ & 96.6 (3.3) & $96.4(3.6)$ & & \\
\hline \multicolumn{7}{|c|}{ DUAL TASK CRT } \\
\hline $\mathrm{N}$ & 36 & 29 & 64 & 59 & & \\
\hline Mean \% correct & $96.7(3.0)$ & $96.1(3.9)$ & $97.2(3.2)$ & 96.4 (3.3) & & \\
\hline No Switch & $98.1(2.7)$ & $97.6(3.1)$ & $98.0(3.4)$ & $97.4(2.7)$ & & \\
\hline Switch & $95.1(4.0)$ & $94.2(5.2)$ & $96.1(3.8)$ & $95.1(4.6)$ & & \\
\hline $\begin{array}{l}\text { Interference } \\
\text { effect }^{\mathrm{C}}\end{array}$ & $1.7(4.5)$ & $1.5(3.5)$ & $0.8(3.4)$ & $-0.1(2.7)$ & & \\
\hline \multicolumn{7}{|l|}{ FLANKER } \\
\hline $\mathrm{N}$ & 36 & 35 & 63 & 61 & & \\
\hline Mean \% correct & $94.5(4.1)$ & $94.5(4.2)$ & $95.1(4.4)$ & $95.8(4.1)$ & & \\
\hline Congruent & $94.8(4.1)$ & $95.3(3.8)$ & $95.7(4.7)$ & $96.5(4.3)$ & & \\
\hline Incongruent & $94.3(5.1)$ & $93.7(5.5)$ & $94.4(5.2)$ & $95.3(4.8)$ & & \\
\hline \multicolumn{7}{|c|}{ ITEM WORKING MEMORY } \\
\hline $\begin{array}{l}\mathrm{N} \\
\text { Mean \% correct }\end{array}$ & $\begin{array}{c}23 \\
81.9(6.0)\end{array}$ & $\begin{array}{c}23 \\
83.2(8.1)\end{array}$ & $\begin{array}{c}43 \\
79.9(7.9)\end{array}$ & $\begin{array}{c}42 \\
82.8(7.0)\end{array}$ & \multirow{4}{*}{$\begin{array}{l}\text { Set size: } F_{(2,126)}=121.86 \\
p<0.001 \\
\text { Target: } F_{(1,63)}=15.64, p<0.001 \\
\text { Session: } F_{(1,63)}=5.44 \\
p=0.023 \\
\text { Sex: } F_{(1,63)}=2.11, p=0.15\end{array}$} & $\begin{array}{l}\text { Set size } \times \text { target: } F_{(2,126)}=10.87 \text {, } \\
p<0.001\end{array}$ \\
\hline Set size: 2 & $93.5(5.1)$ & $90.4(8.2)$ & $90.1(9.3)$ & $92.4(7.7)$ & & Set size $\times$ session: $F_{(2,126)}=2.27$ \\
\hline Set size: 4 & $79.4(7.9)$ & $85.9(8.1)$ & $79.8(12.3)$ & $82.1(11.6)$ & & $\begin{array}{l}p=0.109 \\
\text { Set size } \times \text { sex: } F(2,126)=1.59, p=0.211\end{array}$ \\
\hline Set size: 6 & $73.0(12.2)$ & $77.6(12.0)$ & $70.1(11.9)$ & $71.0(10.3)$ & & $\begin{array}{l}\text { Target } \times \text { session: } F_{(1,63)}=1.33, p=0.253 \\
\text { Target } \times \operatorname{sex:} F_{(1,63)}=2.19, p=0.144 \\
\text { Session } \times \text { sex: } F_{(1,63)}<1, p=0.642 \\
\text { Session } \times \text { target } \times \text { sex: } F_{(1,63)}=1.22, \\
p=0.274\end{array}$ \\
\hline
\end{tabular}


TABLE 4 | Continued

\begin{tabular}{|c|c|c|c|c|c|}
\hline \multirow{2}{*}{$\begin{array}{l}\text { DalCAB Task } \\
\text { variable* }^{*}\end{array}$} & \multicolumn{2}{|c|}{ Male } & Female & \multirow[t]{2}{*}{ Main effects } & \multirow[t]{2}{*}{ Interactions } \\
\hline & $\begin{array}{c}\text { Baseline } \\
\text { Mean (SD) }\end{array}$ & $\begin{array}{c}\text { 24-h } \\
\text { Mean (SD) }\end{array}$ & $\begin{array}{c}\text { Baseline } \\
\text { Mean (SD) }\end{array}$ & & \\
\hline & & & & & $\begin{array}{l}\text { Session } \times \text { set size } \times \text { sex: } \\
\boldsymbol{F}_{(\mathbf{2}, \mathbf{1 2 6})}=\mathbf{3 . 3 3}, \boldsymbol{p}=\mathbf{0 . 0 4} \\
\text { Target } \times \text { set size } \times \text { sex: } \boldsymbol{F}_{(\mathbf{2}, \mathbf{1 2 6})}=\mathbf{3 . 4 8}, \\
\boldsymbol{p}=\mathbf{0 . 0 3 5} \\
\text { Session } \times \text { target } \times \text { set size: } F_{(2,126)}<1, \\
p=0.939 \\
\text { Set size } \times \text { target } \times \text { session } \times \text { sex: } \\
F_{(2,126)}=1.21, p=0.301\end{array}$ \\
\hline \multicolumn{6}{|c|}{ VISUAL SEARCH } \\
\hline $\mathrm{N}$ & 36 & 35 & 64 & 61 & \\
\hline \multicolumn{6}{|c|}{ Feature search } \\
\hline$\%$ correct & $94.3(3.6)$ & $93.7(6.6)$ & $94.1(5.0)$ & $94.6(4.2)$ & \\
\hline Set size: 6 & $94.2(4.7)$ & $93.4(5.8)$ & $94.1(6.1)$ & $94.3(5.8)$ & \\
\hline Set size: 12 & $94.1(5.0)$ & $93.4(7.0)$ & $93.6(5.9)$ & $94.8(5.6)$ & \\
\hline Set size: 18 & $94.5(4.7)$ & $94.1(8.6)$ & $94.5(5.8)$ & 94.7 (4.3) & \\
\hline \multicolumn{6}{|c|}{ Conjunction search } \\
\hline$\%$ correct & $95.6(5.4)$ & $94.6(6.3)$ & $94.8(5.7)$ & $95.6(4.0)$ & \\
\hline Set size: 6 & $95.9(5.1)$ & $93.8(7.1)$ & $94.9(6.7)$ & $95.5(4.5)$ & \\
\hline Set size: 12 & $95.1(6.5)$ & $95.4(5.6)$ & $95.2(6.4)$ & $95.5(5.9)$ & \\
\hline Set size: 18 & 95.7 (6.6) & 94.7 (8.8) & $94.3(6.1)$ & $95.9(4.6)$ & \\
\hline
\end{tabular}

*Please refer to the written results section for a description of select DalCAB task variables on accuracy.

${ }^{a}$ Response-stimulus interval.

${ }^{b}$ False alarm.

${ }^{c}$ Interference effect $=$ dual task mean \% correct $-C R T$ mean \% correct.

Bold indicates significance at the $p<0.05$.

\section{Dual Task}

Eight participants ( 2 women, 6 men) were removed from the dual task CRT analysis due to a complete lack of responding to CRT trials in the 24-h session. Thus, 58 women and 30 men were included in the mixed factor dual task CRT analysis. The mixed factor ANOVA on mean RT (as described above), including the task variable of Trial Type (switch, non-switch) revealed the expected pattern of switch costs; participants were slower to respond when the stimulus/response changed on consecutive trials (i.e., $\mathrm{M}_{\mathrm{RT}} \pm \mathrm{SE}$ switch trials $=581.4 \pm 10.7 \mathrm{~ms}$ ) than when the stimulus/response remained the same [i.e., $\mathrm{M}_{\mathrm{RT}} \pm \mathrm{SE}$ non-switch trials $=436.6 \pm 6.69 \mathrm{~ms} ; F_{(1,86)}=583.16$, $M S E=2796.3, p<0.001$, Table 3]. A significant practice effect for mean RT indicated that participants were significantly faster at 24-h than at baseline $\left(\mathrm{M}_{\mathrm{RT} \text { baseline } \pm \mathrm{SE}}=539.5 \pm 8.8 \mathrm{~ms}\right.$, $\left.\mathrm{M}_{\mathrm{RT} 24-\mathrm{h} \pm \mathrm{SE}}=483.38 \pm 7.5 \mathrm{~ms}, p<0.001\right)$. This improvement in performance RT between baseline and 24-h was paired with a decrease in performance accuracy (percent correct), suggesting a speed-accuracy trade-off ( $\mathrm{M}_{\mathrm{PC} \text { baseline } \pm \mathrm{SE}}=97 \pm 0.32 \%$, $\mathrm{M}_{\mathrm{PC} 24-\mathrm{h} \pm \mathrm{SE}}=96 \pm 0.37 \%, p<0.001$, not presented in table). The RT switch cost and WM load RT effect were also significantly reduced 24-h after baseline $\left(\mathrm{M}_{\mathrm{RT}}\right.$ switch cost baseline $\pm \mathrm{SE}=152.19$ $\pm 6.2 \mathrm{~ms}, \mathrm{M}_{\mathrm{RT}}$ switch cost $24-\mathrm{h} \pm \mathrm{SE}=140.52 \pm 5.6 \mathrm{~ms}, p=0.037$; $\mathrm{M}_{\mathrm{WM} \text { load RT baseline } \pm \mathrm{SE}}=107.18 \pm 7.2, \mathrm{M}_{\mathrm{WM} \text { load RT 24-h } \pm \mathrm{SE}}$ $=79.34 \pm 6.2 \mathrm{~ms}, p<0.001$; Table 5). No significant practice effects were found for the DT interference effect (Table 5) indicating that the additional workload from adding a secondary task to the choice reaction time task did not change across testing sessions.

The ICC scores for mean RTs and the RT switch cost at 24-h interval were in the Good to Very Good range (Mean RT: 0.781 and RT switch cost: 0.817; Table 5). The test-retest reliability score for the WM load RT effect (difference in reaction time performance between the dual tasks and CRT) 24-h after baseline was Good (0.735), but the dual task interference effect (difference in accuracy between dual task CRT and CRT) was below the Good range (0.496).

\section{Flanker}

The mixed factor ANOVA on mean reaction time including the task variable of Flanker Congruency (congruent, incongruent) revealed that RTs were faster for congruent trials than incongruent trials [congruent $=452.8 \pm 5.6 \mathrm{~ms}$, incongruent $=$ $\left.470.2 \pm 5.5 \mathrm{~ms} ; F_{(1,94)}=105.11, M S E=256.05, p<0.001\right]$. RTs for male performance were also faster than RTs for female performance $[$ males $=447.6 \pm 8.8 \mathrm{~ms}$, females $=475.4 \pm 6.7 \mathrm{~ms}$; $F_{(1,94)}=6.29, M S E=10903.81, p=0.014$, Table 3]. A significant practice effect for mean RT was found; participants were faster at 24-h than at baseline $\left(\mathrm{M}_{\mathrm{RT}} 24-\mathrm{h} \pm \mathrm{SE}=458.74 \pm\right.$ $6.01 \mathrm{~ms}, \mathrm{M}_{\mathrm{RT}}$ baseline $\pm \mathrm{SE}=471.90 \pm 5.55 \mathrm{~ms}, p<0.05$, Tables 3, 5). The RT interference effect did not differ across testing sessions (Table 5).

The test-retest reliability score of mean RTs at the 24-h session was Very Good (0.871). However, the test-retest 
TABLE 5 | Change-based reliability statistics for participants 24-h after baseline.

\begin{tabular}{|c|c|c|c|c|}
\hline \multirow[t]{2}{*}{ DalCAB Task } & \multicolumn{4}{|c|}{ 24-h } \\
\hline & ICC & PE & $S_{D}$ & Cohen's d \\
\hline \multicolumn{5}{|l|}{ SRT } \\
\hline $\mathrm{N}$ & & 95 & & \\
\hline Mean RT & $0.825^{\#}$ & $-2.7 \mathrm{~ms}$ & $35.6 \mathrm{~ms}$ & 0.07 \\
\hline $\mathrm{RT}$ preparation effect $^{\mathrm{a}}$ & $0.570^{\#}$ & $-6.1 \mathrm{~ms}$ & $37.8 \mathrm{~ms}$ & 0.16 \\
\hline \multicolumn{5}{|l|}{ GNG } \\
\hline $\mathrm{N}$ & 96 & & & \\
\hline $20 \%$ Go RT & $0.836^{\#}$ & $0.4 \mathrm{~ms}$ & $35.8 \mathrm{~ms}$ & 0.01 \\
\hline $20 \%$ Go: $\%$ FAb & 0.252 & $-0.1 \%$ & $0.8 \%$ & 0.07 \\
\hline $80 \%$ Go RT & $0.847^{\#}$ & $-9.7 \mathrm{~ms}^{*}$ & $31.2 \mathrm{~ms}$ & 0.32 \\
\hline $80 \%$ Go: $\%$ FA & $0.548^{\#}$ & $2.4 \% *$ & $9.2 \%$ & 0.27 \\
\hline \multicolumn{5}{|l|}{ CRT } \\
\hline $\mathrm{N}$ & & 96 & & \\
\hline Mean RT & $0.749^{\#}$ & $-24.0 \mathrm{~ms}^{\star}$ & $46.8 \mathrm{~ms}$ & 0.51 \\
\hline RT switch cost ${ }^{\mathrm{C}}$ & $0.609^{\#}$ & $2.4 \mathrm{~ms}$ & $36.6 \mathrm{~ms}$ & 0.07 \\
\hline \multicolumn{5}{|l|}{ DUAL TASK CRT } \\
\hline $\mathrm{N}$ & & 88 & & \\
\hline Mean RT & $0.781^{\#}$ & $-50.4 \mathrm{~ms}^{*}$ & $53.0 \mathrm{~ms}$ & 0.99 \\
\hline RT switch cost ${ }^{\mathrm{C}}$ & $0.817^{\#}$ & $-10.0 \mathrm{~ms}^{\star}$ & $44.3 \mathrm{~ms}$ & 0.23 \\
\hline WM load RT effect ${ }^{d}$ & $0.735^{\#}$ & $-26.0 \mathrm{~ms}^{\star}$ & $54.2 \mathrm{~ms}$ & 0.48 \\
\hline DT Interference effect ${ }^{e}$ & $0.496^{\#}$ & $-0.7 \%$ & $3.7 \%$ & 0.18 \\
\hline \multicolumn{5}{|l|}{ FLANKER } \\
\hline $\mathrm{N}$ & & 96 & & \\
\hline Mean RT & $0.871^{\#}$ & $-13.2 \mathrm{~ms}^{\star}$ & $36.6 \mathrm{~ms}$ & 0.36 \\
\hline RT Interference effect ${ }^{f}$ & 0.301 & $-0.7 \mathrm{~ms}$ & $26.7 \mathrm{~ms}$ & 0.02 \\
\hline \multicolumn{5}{|l|}{ ITEM MEMORY } \\
\hline $\mathrm{N}$ & & 65 & & \\
\hline Mean RT & $0.795^{\#}$ & $-57.8 \mathrm{~ms}^{*}$ & $81.1 \mathrm{~ms}$ & 0.71 \\
\hline Set-size RT slope & $0.623^{\#}$ & $-3.5 \mathrm{~ms}$ & $26.4 \mathrm{~ms}$ & 0.14 \\
\hline$\%$ correct & 0.417 & $2.5 \%$ * & $8.7 \%$ & 0.29 \\
\hline \multicolumn{5}{|l|}{ VISUAL SEARCH } \\
\hline $\mathrm{N}$ & & 96 & & \\
\hline \multicolumn{5}{|l|}{ Feature search } \\
\hline Mean RT & $0.770^{\#}$ & $-35.9 \mathrm{~ms}^{\star}$ & $77.4 \mathrm{~ms}$ & 0.49 \\
\hline Set-size RT slope & $0.096^{\#}$ & $0.30 \mathrm{~ms}$ & $6.70 \mathrm{~ms}$ & 0.06 \\
\hline \multicolumn{5}{|l|}{ Conjunction search } \\
\hline Mean RT & $0.718^{\#}$ & $-163.2 \mathrm{~ms}^{\star}$ & $142.4 \mathrm{~ms}$ & 1.19 \\
\hline Set-size RT slope & $0.464^{\#}$ & $-9.29 \mathrm{~ms}^{*}$ & 19.91 & 0.53 \\
\hline
\end{tabular}

Bold numbers highlight good to very good reliability and significantly large practice effects. ICC, Intraclass correlation (two-way random, absolute agreement, average measures); \#, significant F-test $(p<0.01)$; Practice effect $(P E)$, post session mean-baseline mean; *significant difference based on paired t-test $(p<0.05)$; $S D_{D}$, standard deviation of the difference score.

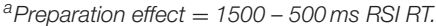

${ }^{b}$ False alarm.

${ }^{c}$ Switch cost $=R T$ Switch - RT No-switch.

${ }^{d}$ Working memory load $R T$ effect $=$ dual task mean minus CRT mean

${ }^{e} D T$ interference effect $=$ dual task CRT accuracy - CRT accuracy.

${ }^{f}$ Interference effect = incongruent $R T$ - congruent $R T$.

reliability scores for the RT interference effect (i.e., incongruent RT minus congruent RT) was less than Good (0.301, Table 5).

\section{Item Working Memory}

Due to changes in programming, the final version of the item working memory task was not completed by all participants ( $n=65 ; 42$ female). The mixed factor ANOVA on mean reaction time including the task variables of Set Size $(2,4,6)$ and Target (present, absent) revealed the anticipated effect of Set Size, such that RTs were significantly slowed for each additional two-item increase in working memory set size $\left[F_{(2,126)}=220.24, M S E=\right.$ $11292.38, p<0.001$; Set $2=701.4 \pm 11.8 \mathrm{~ms}$, Set $4=830.0 \pm$ $13.4 \mathrm{~ms}$, Set $6=904.5 \pm 15.7 \mathrm{~ms}$, all $p<0.001]$ and accuracy (percent correct) significantly decreased for each additional twoitem increase in working memory set size (Set $2=92 \pm 0.8 \%$, Set $4=82 \pm 11 \%$, Set $6=73 \pm 12 \%$, all $p<0.001)$. A significant interaction between Set size and Target was also found for reaction time $\left[F_{(2,126)}=3.64, M S E=8039.09, p=0.03\right]$; post-hoc pairwise comparisons indicated the same pattern of effect of Set size on RTs for both target absent and target present trial types (all $p<0.01$; mean RT is presented collapsed across target in Tables 3, 4). Two significant three way interactions for percent correct were also found. An interaction among Set size, Target and Sex $\left[F_{(2,126)}=3.48, p=0.035\right]$ revealed the above reported decrease in percent correct performance across working memory set size increase for women, regardless of Target. In contrast, for men, a decrease in accuracy was found between Set 2 and Set 6 for both Target types, but only between Set 4 and Set 6 when the Target was present in the working memory set. (Target Absent: Set 2: 93\%, Set 4: 75\%, Set 6: 69\%; Target Present: Set 2: 91\%, Set 4: $90 \%$, Set 6: $82 \%)$. Similarly, the interaction between Session, Set size and Sex $\left[F_{(2,126)}=3.33, p=0.04\right]$ revealed the above described decrease in accuracy across Set size for women, regardless of session, but not for men (Session 1: Set $2>$ Set 4 , $p<0.001$; Set $2>$ Set $6, p<0.001$; Set $4=$ Set $6, p=0.164$; Session 2: Set $2=$ Set $4, p=1.0$; Set $2>$ Set $6, p=0.007$; Set $4>$ Set $6, p=0.006$; mean percent correct is presented collapsed across target type in Table 4).

A significant practice effect for mean RT indicated that participants were faster at 24-h than at baseline $\left(\mathrm{M}_{\mathrm{RT}} 24-\mathrm{h} \pm \mathrm{SE}\right.$ $=780.77 \pm 14.31 \mathrm{~ms}, \mathrm{M}_{\mathrm{RT}}$ baseline $\pm \mathrm{SE}=838.54 \pm 13.77 \mathrm{~ms}$, $p<0.001)$; participants were also more accurate at 24-h than at baseline (Table 5). The practice effect for the set size RT slope was not significant.

The test-retest reliability score for mean RTs at the 24-h session was in the Good range (0.795), whereas the ICC scores for the set size slope and mean percent of correct responses $\left(\mathrm{M}_{\mathrm{PC}}\right)$ fell below the Good range ( 0.623 and 0.417 , respectively).

\section{Visual Search}

Mixed factor ANOVAs on mean reaction time including the task variable of Set Size $(6,12$, and 18) were performed for each Search Type (feature, conjunction) separately.

In the feature search task, a significant main effect of Set Size was found; RTs were faster for the smallest set than the two larger set sizes, which did not differ $\left[F_{(2,188)}=7.46, M S E=1504.13\right.$, $p<0.001$; Set $6=619.4 \pm 8.8 \mathrm{~ms}$, Set $12=630.9 \pm 10.1 \mathrm{~ms}$, Set $18=634.4 \pm 11.0 \mathrm{~ms}$; Set $6<$ Set $12, p=0.008$; Set $6<$ Set $18, p=0.004$; Set $12=$ Set $18, p=1.0]$. While the set size main effect was significant, it should be noted that search 
slopes were small and almost 0 (range from $<1$ to $2 \mathrm{~ms} /$ item), in line with other feature search tasks (reviewed in Wolfe, 1998). A significant practice effect for mean RT was found in the feature search task; participants' mean RT was faster at 24-h than at baseline $\left(\mathrm{M}_{\mathrm{RT}} 24-\mathrm{h} \pm \mathrm{SE}=610.25 \pm 8.22 \mathrm{~ms}, \mathrm{M}_{\mathrm{RT}}\right.$ baseline $\pm \mathrm{SE}=$ $646.16 \pm 10.96 \mathrm{~ms}, p<0.001)$, but there was no change in the set size slope. The ICC score for mean RTs was in the Good range (0.770, Table 5).

In the conjunction search task, a significant main effect of Set Size was also found (slopes ranging from 46 to $51 \mathrm{~ms} /$ item), although qualified by a significant Session $\times$ Set Size interaction $\left[F_{(2,188)}=13.77, M S E=1565.64, p<0.001\right]$. Post-hoc analysis of the interaction showed that while RTs increased significantly as a function of set size in each session (i.e., the anticipated set size effect) and RTs were faster at the 24-h session than the baseline session for each set size (consistent with practice effects, Table 5), the set size slope decreased between baseline and the 24-h session. This interaction reflects the significant practice effects found in the conjunction search task for mean RT and set-size slope; participants were significantly faster overall and showed a smaller set size slope at 24-h than at baseline $\left(\mathrm{M}_{\mathrm{RT}} 24-\mathrm{h} \pm \mathrm{SE}=1130.5 \pm\right.$ $18.2 \mathrm{~ms}, \mathrm{M}_{\mathrm{RT}}$ baseline $\left.\pm \mathrm{SE}=1293.7 \pm 22.4 \mathrm{~ms}, p<0.001\right)$. The ICC score for mean RTs for the conjunction visual search task was also in the Good range (0.718, Table 5).

\section{DISCUSSION}

The current study presents a unique look at average performance (reaction time, accuracy), 24-h practice effects and reliability data for seven common attention test paradigms integrated as sub-tests of the DalCAB in a sample of 96 healthy adults (18-31 years of age). These results provide the first normative data for the DalCAB and present preliminary information on the psychometric properties of performance on several tasks previously used in the cognitive neuroscience field to assess separate aspects of attention ${ }^{5}$. These tasks are combined within the DalCAB which employs standardized stimuli across all tasks, allowing comparisons across attention functions using multiple test measures.

\section{Test-Retest Reliability}

Our primary goal was to examine the stability of performance on tasks of the DalCAB by examining the test-retest reliability of the DalCAB outcome measures over a short period of time $(24 \mathrm{~h})$. Test-retest reliability in performance is an important property to consider in cognitive or clinical neuroscience research, particularly with repeated testing paradigms or for evaluating change in performance patterns over time. At a re-test interval of $24 \mathrm{~h}$, we found that all reliability coefficients for mean raw RT scores on the individual DalCAB subtests demonstrated Good to Very Good test-retest reliability, ranging from 0.718 to 0.871 . These values are similar to or better than reliability findings on RT tasks from other batteries by young and older subjects at a variety of test-retest intervals (e.g., Secker et al., 2004; Falleti et al.,

\footnotetext{
${ }^{5}$ The conclusions drawn here are based on a relatively homogenous sample of adults; further research is needed before the normative data presented here can be interpreted in the context of other groups or in clinical settings.
}

2006, Table 1; Williams et al., 2005, Table 3; Lowe and Rabbitt, 1998; Nakayama et al., 2014).

In contrast, although the Dual Task CRT switch cost maintained Very Good reliability and the Dual Task Working Memory Load Effect was above 0.700 at the 24-h interval, in general, the test-retest reliability of RT-difference measures (e.g., SRT preparation effect, CRT switch cost, Flanker interference effect) tended to be less robust than the reliability of mean performance RT.

The pattern of lower test-retest reliability for difference performance measures on the DalCAB is similar to that reported for the ANT (Fan et al., 2002; MacLeod et al., 2010). For example, MacLeod et al. (2010), using data derived from a large sample of 15 studies, reported low split-half reliability for the vigilance and orienting difference measures computed from the ANT ( 0.38 and 0.55 , respectively) while the executive score reliability was higher (0.81). Assessments of the test-retest reliability of the ANT and ANT-I have also revealed variations in the reliability of the three difference scores used to describe attention network efficiency, with the executive control score reported as the most reliable and the vigilance score reported as the least reliable (Fan et al., 2002; Ishigami and Klein, 2010; Ishigami et al., 2016). Due to the nature of correlation analysis, test-retest reliability findings obtained from calculation of difference scores that are highly correlated could be less reliable (discussed in MacLeod et al., 2010). These findings should lend some caution to the use of difference scores as sole measures of attentional function. The reliability of the DalCAB is also lower than the ANT reliability overall, likely due to the fact that the ANT has more trials.

Test-retest reliability of performance accuracy was also analyzed on all tasks. However, given our sample of healthy adults (18-31 years of age), accuracy was high across all administrations of the DalCAB (as presented in Table 4) and thus we presented performance accuracy results in the Go/NoGo and Item working memory tasks only (Table 5). Test-retest reliability coefficients for the Go/No-Go and Item working memory performance accuracy measures were lower than those observed for performance RT, perhaps due to the low variance in these measures given our sample (see also a discussion by Falleti et al., 2006 about ceiling and floor effects). For example, in the $\mathrm{Go} / \mathrm{No}-\mathrm{Go}$ task, false alarms in the $20 \%$ go frequency task were very low, ranging from 0.2 to $0.6 \%$ and thus reliability was also very low (0.252). In contrast, the frequency of false alarms in the $80 \%$ go frequency task ranged from 6.6 to $12.9 \%$ and thus testretest reliability was higher (0.548). We also found that reliability of percent correct in the Item Working Memory task of the DalCAB also fell well below our definition of Good (0.417) at the 24-h interval.

Hahn et al. (2011, Table 2) reported ICCs falling below 0.700 in healthy adults (Mean age $=33$ years) for the alerting $(0.166)$ and orienting (0.109) accuracy measures, as well as the overall mean accuracy measure (0.553) on the ANT (Fan et al., 2002). Similarly, using the Continuous Performance Test-II (Conners, 2000), Zabel et al. (2009) reported test-retest reliability scores of 0.39 and 0.57 on omission and commission errors, respectively, in a sample of healthy children (6-18 years); these ICCs were less than that reported for reaction times on hit trials $(\mathrm{ICC}=0.65)$. 
In contrast, Wöstmann et al. (2013, Table 2) reported an ICC of 0.84 for commission errors in the No-go portion of a Go/Nogo task approximately 28 days following baseline, suggesting Very Good (0.800) test-retest reliability for this measure (in healthy 18-55 year olds). These authors also reported ICCs of 0.51 and 0.48 for accuracy of responses to number and shape stimuli in a continuous performance test (participants were instructed to remove their finger from a button when identical consecutive stimuli were presented; Wöstmann et al., 2013, Table 2). As accuracy measures, particularly those measured in healthy populations, tend to approach ceiling, it is possible that the Go/No-go and Item working memory performance accuracy measures with our current sample are not sufficiently varied to provide a representative account of test-retest reliability. This could be one reason why the ICCs for accuracy measures are often reported to be lower overall than the corresponding RT scores (e.g., Llorente et al., 2001; Messinis et al., 2007; Zabel et al., 2009; Hahn et al., 2011; Wöstmann et al., 2013). In the case of the DalCAB assessment presented here, participants were highly accurate in all presentations of both the Go/No-go and Item working memory tasks.

Overall, we found Good to Very Good test-retest reliability (ICC range: 0.718 to 0.871 ) on all of our mean reaction time measures for each of the DalCAB tasks, suggesting that the mean reaction time performance measures in all DalCAB tasks would allow for measurement of attention across short duration (24 h) repeated testing sessions. We also found much lower testretest reliability (less than Good) for computed reaction time difference scores (ICC range: 0.096-0.62) and accuracy measures (ICC range: $0.25-0.548$ ) indicating the lack of reliability these measures could offer across repeated testing sessions.

\section{Practice Effects}

While significant practice effects on computerized tests of attention and executive functions are common across various time periods (minutes, hours, and weeks), the practice effects on computerized batteries have tended to be largest between the first and second assessment and then remain stable over further presentations (Collie et al., 2003; Falleti et al., 2006). The DalCAB data revealed large and significant practice effects at the 24 -h re-test interval on most tasks. Our results illustrate that participants were faster to respond in the repeat 24-h session than in the baseline session for all tasks except Simple Reaction Time and Go/No-Go: 20\%-Go. In addition, although accuracy did not generally differ across sessions for the tasks, there were more anticipations (i.e., decreased accuracy) in the Simple Reaction Time task in the 24-h session than at baseline (Table 4). The lack of practice effects and decreased accuracy in performance on these basic alertness/vigilance tasks could suggest that the healthy adults maintained alertness and maximized their speed on both testing occasions, but were not as engaged and responded more haphazardly on repeated exposure to the SRT task; i.e., more transient arousal changes when the task was no longer novel (Steinborn and Langner, 2012). In previous research, while many behavioral measures exhibit practice effects, those requiring problem-solving and strategy use tend to show the greatest practice effects (Lezak, 1995; Dikmen et al., 1999). Thus, the practice effects apparent on more complex DalCAB tasks are likely related to improvements in processes rather than basic speed of responding, which was apparently maximized in both sessions.

In the dual task CRT trials, participants were faster and less accurate in the 24-h session than at baseline (Tables 3, 4). It should be noted that, in the 24-h session, eight participants failed to make responses to the CRT-trials while they completed the concurrent color-counting task of the dual task and others were prompted by the experimenter to make a buttonpress to each stimulus presented-these participants were not included in the analysis of the dual task. Regardless, the higher number of missed/incorrect responses and related decrease in percent correct CRT responses in the current data may reflect interference by the color-counting task; i.e., the color-counting task is so resource intensive for some participants that the concurrent CRT task is stopped completely. Thus, it is possible that there are two separate processes measurable by the DalCAB Dual Task: a working memory load effect (i.e., increase in CRT $\mathrm{RT}$ in the dual task compared to the single CRT task) and an interference effect (i.e., increase in misses in the dual task CRT vs. the single task CRT).

\section{Interpreting the DalCAB: Future Assessments of Validity}

We have not formally examined the validity of our interpretation of the DalCAB here. Nonetheless, as the tasks included in the $\mathrm{DalCAB}$ are based on tasks purported to measure vigilance, orienting and executive control functions in cognitive psychology research, as a starting point, it is prudent to ensure that performance on each task is replicating performance patterns previously reported in the cognitive psychology literature. Overall, RT performance across the levels of the independent variables of interest in each DalCAB task followed the expected patterns, as summarized in Table 1. Therefore, our results might indirectly provide a preliminary assessment of the convergent validity of our interpretation of the DalCAB and, at the very least, justify a formal gathering of validity evidence for our interpretation of the DalCAB in the future.

The current findings are consistent with the interpretation of other analyses performed on these same data that examined the factor structure of performance on the DalCAB (Jones et al., 2015). Specifically, we used exploratory and confirmatory factor analysis to examine the preliminary factor structure and reliable common variance in $\mathrm{RT}$ and accuracy performance related to the variables incorporated into the DalCAB tasks. The resulting extracted model had 9 factors. We reported that: (1) each of the nine-factors are related to one of the vigilance, orienting and executive control networks and; (2) multiple measures derived from the same DalCAB tasks are associated with more than one factor, highlighting the importance of each of the specific tasks and measures selected from the DalCAB in measuring the functions of attention (Jones et al., 2015).

\section{LIMITATIONS}

The conclusions we have drawn about the reliability of DalCAB performance are based on a small sample of healthy adults $(n=$ 
96). Our sample size is comparable to other studies exploring test-retest and split-half reliability for other computerized neuropsychological batteries (e.g., MicroCog: Raymond et al., 2006, $n=40$, test-retest; CPT-PENN: Kurtz et al., 2001, $n=$ 80, alternate forms; IntegNeuro: Williams et al., 2005, $n=$ 21, test-retest (normative data base of over 1000); CogState: (Falleti et al., 2006), $n=45$, test-retest and practice effects at a short time interval; $n=55$, test-retest and practice effects at a longer time interval; Darby et al., 2002, $n=20$ patients with mild cognitive impairment, $n=40$ healthy control participants, test-retest; Collie et al., 2003, $n=113$, test-retest). However, our sample is also homogeneous in nature, such that participants were recruited from a post-secondary environment, are highly educated, healthy and represent a small age range. As such, further research is needed before the normative data presented here can be interpreted in the context of other groups or in clinical settings. Ongoing research in our lab will gather evidence for the validation of our interpretation of the DalCAB (criterion and discriminant validity) by comparing the DalCAB to gold-standard neuropsychological tests of attention and examining the reliability of the DalCAB in healthy older adults (Rubinfeld et al., 2014). We have also recently submitted work on ensuring chronometric (clock) precision in the measurement of reaction time using computer-based tasks, using the DalCAB as an example (Salmon et al., submitted). Thus, the DalCAB holds promise for future use in research and clinical environments.

\section{CONCLUSIONS}

Here, we sought to evaluate the test-retest reliability of the DalCAB over a short interval of 24-h. Our evaluation of the reliability and practice effects on performance of the tasks in the DalCAB indicate Good to Very Good test-retest reliability for mean RTs on all tasks and significant practice effects on mean RTs at 24-h after baseline for most tasks

\section{REFERENCES}

Adolfsdottir, S., Sorensen, L., and Lundervold, A. J. (2008). The attention network test: a characteristic pattern of deficits in children with ADHD. Behav. Brain Funct. 4:9. doi: 10.1186/1744-9081-4-9

AhnAllen, C. G., Nestor, P. G., Shenton, M. E., McCarley, R. W., and Niznikiewicz, M. A. (2008). Early nicotine withdrawal and transdermal nicotine effects on neurocogitive performance in schizophrenia. Schizophr. Res. 100, 261-269. doi: 10.1016/j.schres.2007.07.030

Baddeley, A. D. (2012). Working memory: theories, models and controversies. Annu. Rev. Psychol. 63, 1-29. doi: 10.1146/annurev-psych-120710-1 00422

Baddeley, A., and Della Sala, S. (1996). Working memory and executive control. Philos. Trans. R. Soc. Lond. B Biol. Sci. 351, 1397-1403. discussion: 1403-1394.

Baddeley, A. D., and Hitch, G. (1974). "Working memory," in The Psychology of Learning and Motivation: Advances in Research and Theory, Vol. 8, ed G. H. Bower (New York, NY: Academic Press), 47-89.

Bailon, O., Roussel, M., Boucart, M., Krystkowiak, P., and Godefroy, O. (2010). Psychomotor slowing in mild cognitive impairment, Alzheimer's disease and lewy body dementia: mechanisms and diagnostic value. Dement. Geriatr. Cogn. Disord. 29, 388-396. doi: 10.1159/000305095
(5/7 tasks). We have also presented preliminary normative data that supports our interpretation of performance on the DalCAB, taking into account our small, homogenous sample. In particular, we report task-related effects that are consistent with those previously reported in the literature for similar tasks. Although validity was not formally assessed here, these preliminary findings might serve as pilot data, supporting future assessments of the convergent validity of our interpretation of the DalCAB as a measure of attention.

\section{AUTHOR CONTRIBUTIONS}

SJ contributed to the conception of the study, established procedures for data analysis, aided in the analysis and interpretation of the data and aided in the preparation of the manuscript. BB contributed to the conception of the study, participated in the design of the study, aided in the analysis and interpretation of the data and aided in the preparation of the manuscript. FK participated in the acquisition of the data and aided in the preparation of the manuscript. AJ contributed to analysis of the data and aided in preparation of the manuscript. RK contributed to the conception of the study, the interpretation of the data and aided in preparation of the manuscript. GE contributed to the conception of the study, the interpretation of data, participated in the design of the study, and aided in the preparation of the manuscript. All authors read and approved the final manuscript.

\section{FUNDING}

Funding for this research was provided by the Atlantic Canada Opportunities Agency, Atlantic Innovation Fund (to GE, RK), Springboard Technology Development Program Award (to GE), and the Dalhousie Department of Psychiatry Research Fund (to $\mathrm{BB}, \mathrm{GE})$.
Barker-Collo, S., Feigin, V. L., Lawes, C. M. M., Parag, V., and Senior, H. (2010). Attention deficits after incident stroke in the acute period: frequency across types of attention and relationships to patients characteristics and functional outcomes. Top. Stroke Rehabil. 17, 463-476. doi: 10.1310/tsr1706-463

Bronnick, K., Ehrt, U., Emre, M., DeDeyn, P. P., Wesnes, K., Tekin, S., et al. (2006). Attentional deficits affect activities of daily living in dementia-associated with Parkinson's disease. J. Neurol. Neurosurg. Psychiatry 77, 1136-1142. doi: 10.1136/jnnp.2006.093146

Bundensen, C. (1990). A theory of visual attention. Psychol. Rev. 97, 523-547. doi: 10.1037/0033-295X.97.4.523

Butler, B. C., Eskes, G. A., and Klein, R. M. (2010). "Measuring the Components of Attention," in Poster at the 25th Annual Meeting of the Canadian Society for Brain Behaviour and Cognitive Science (CSBBCS) (Halifax, NS), 324.

Callejas, A., Lupiàñez, J., Funes, M. J., and Tudela, P. (2005). Modulations among the alerting, orienting and executive control networks. Exp. Brain Res. 167, 27-37. doi: 10.1007/s00221-005-2365-z

Carter, L., Russell, P. N., and Helton, W. S. (2013). Target predictability, sustained attention, and response inhibition. Brain Cogn. 82, 35-42. doi: 10.1016/j.bandc.2013.02.002

Chan, R. C., Wang, L., Ye, J., Leung, W. W., and Mok, M. Y. (2008). A psychometric study of the test of everyday attention for children in the 
chinese setting. Arch. Clin. Neuropsychol. 23, 455-466. doi:10.1016/j.acn.2008. 03.007

Chen, H.-C., Koh, C.-L., Hsieh, C.-L., and Hsueh, I.-P. (2009). Test-re-test reliability of two sustained attention tests in persons with chronic stroke. Brain Injury 23, 715-722. doi: 10.1080/02699050903013602

Christie, J., Hilchey, M. D., and Klein, R. M. (2013). Inhibition of return is at the midpoint of simultaneous cues. Atten. Percept. Psychophys. 75, 1610-1618. doi: 10.3758/s13414-013-0510-5

Claros-Salinas, D., Bratzke, D., Greitemann, G., Nickisch, N., Ochs, L., and Schroter, H. (2010). Fatigue-related diurnal variations of cognitive performance in multiple sclerosis and stroke patients. J. Neurol. Sci. 295, 75-81. doi: 10.1016/j.jns.2010.04.018

Collie, A., Maruff, P., Darby, D. G., and McStephen, M. (2003). The effects of practice on the cognitive test performance of neurologically normal individuals assessed at brief test-retest intervals. J. Int. Neuropsychol. Soc. 9, 419-428. doi: $10.1017 /$ S1355617703930074

Conners, C. K. (2000). Conners' Continuous Performance Test, 2 nd Edn. Toronto, ON: Multi-Health Systems, Inc.

Corbetta, M., and Shulman, G. L. (2002). Control of goal-directed and stimulus-driven attention in the brain. Nat. Rev. Neurosci. 3, 201-215. doi: $10.1038 /$ nrn755

Cowan, N. (1988). Evolving conceptions of memory storage, selective attention, and their mutual constraints within the human information-processing system. Psychol. Bull. 104, 163-191.

Cowan, N. (1998). Visual and auditory working memory capacity. Trends Cogn. Sci. 2, 77-78.

Cumming, T. B., Brodtmann, A., Darby, D., and Bernhardt, J. (2014). The importance of cognition to quality of life after stroke. J. Psychosom. Res. 77, 374-379. doi: 10.1016/j.jpsychores.2014.08.009

D'Aloisio, A., and Klein, R. M. (1990). "Aging and the deployment of visual attention," in The Development of Attention: Research and Theory, ed J. T. Enns (North-Holland: Elsevier Science Publishers B.V.), 447-466.

Dalrymple-Alford, J. C., Kalders, A. S., Jones, R. D., and Watson, R. W. (1994). A central executive deficit in patients with Parkinson's disease. J. Neurol. Neurosurg. Psychiatry, 57, 360-367.

Darby, D. G., Maruff, P., Collie, A., and McStephen, M. (2002). Mild cognitive impairment can be detected by multiple assessments in a single day. Neurology, 59, 1042-1046. doi: 10.1038/nrn1302

Davis, E. T., and Palmer, J. (2004). Visual search and attention: an overview. Spat. Vis. 17, 249-255. doi: 10.1163/1568568041920168

Della Sala, S., Baddeley, A., Papagno, C., and Spinnler, H. (1995). Dual-task paradigm: a means to examine the central executive. Ann. N.Y. Acad. Sci. 769, 161-171. doi: 10.1111/j.1749-6632.1995.tb38137.x

Della Sala, S., Cocchini, G., Logie, R. H., Allerhand, M., and MacPherson, S. E. (2010). Dual task during encoding, maintenance, and retrieval in Alzheimer's disease. J. Alzheimers Dis. 19, 503-515. doi: 10.3233/JAD-2010-1244

Dikmen, S. S., Heaton, R. K., Grant, I., and Temkin, N. R. (1999). Test-retest reliability and practice effects of expanded Halstead-Reitan Neuropsychological Test Battery. J. Int. Neuropsychol. Soc. 5, 346-356. doi: $10.1017 /$ S1355617799544056

Dimoska-Di Marco, A., McDonald, S., Kelly, M., Tate, R., and Johnstone, S. (2011). A metaanalysis of response inhibition and Stroop interference control deficits in adults with traumatic brain injury (TBI). J. Clin. Exp. Neuropsychol. 33, 471-485. doi: 10.1080/13803395.2010.533158

Dosenbach, N. U. F., Fair, D. A., Miezin, F. M., Cohen, A. L., Wenger, K. K., Dosenbach, R. A., et al. (2007). Distinct brain networks for adaptive and stable task control in humans. Proc. Natl. Acad. Sci. U.S.A. 104, 11073-11078. doi: 10.1073/pnas.0704320104

Eriksen, B. A., and Eriksen, C. W. (1974). Effects of noise letters upon the identification of a target letter in a nonsearch task. Percept. Psychophys. 16, 143-149. doi: 10.3758/BF03203267

Eskes, G., Jones, S. A. H., Butler, B., and Klein, R. (2013 November). “Measuring the brain networks of attention in the young healthy adult population," in Paper presented at the Society for Neuroscience (San Diego, CA).

Falleti, M. G., Maruff, P., Collie, A., and Darby, D. G. (2006). Practice effects associated with the repeated assessment of cognitive function using the CogState battery at 10-minute, one week and one month test-retest intervals. J. Clin. Exp. Neuropsychol. 28, 1095-1112. doi: 10.1080/13803390500205718
Fan, J., Gu, X., Guise, K. G., Liu, X., Fossella, J., Wang, H., et al. (2009). Testing the behavioral interaction and integration of attentional networks. Brain Cogn. 70, 209-220. doi: 10.1016/j.bandc.2009.02.002

Fan, J., McCandliss, B. D., Sommer, T., Raz, A., and Posner, M. I. (2002). Testing the efficiency and independence of attentional networks. J. Cogn. Neurosci. 14, 340-347. doi: 10.1162/089892902317361886

Fernandez-Duque, D., and Black, S. E. (2006). Attentional networks in normal aging and Alzheimer's disease. Neuropsychology 20, 133-143. doi: 10.1037/0894-4105.20.2.133

Ferraro, F. R., and Balota, D. A. (1999). Memory scanning performance in healthy young adults, healthy older adults, and individuals with dementia of the Alzheimer type. Aging Neuropsychol. Cogn. 6, 260-272. doi: 10.1076/13825585(199912)06:04;1-B;FT260

Fleck, D. E., Kotwal, R., Eliassen, J. C., Lamy, M., Delbello, M. P., Adler, C. M., et al. (2011). Preliminary evidence for increased frontosubcortical activation on a motor impulsivity task in mixed episode bipolar disorder. J. Affect. Disord. 133, 333-339. doi: 10.1016/j.jad.2011.03.053

Foster, J. K., Behrmann, M., and Stuss, D. T. (1999). Visual attention deficits in Alzheimer's disease: simple versus conjoined feature search. Neuropsychology 13, 223-245. doi: 10.1037/0894-4105.13.2.223

Godefroy, O., Lhullier-Lamy, C., and Rousseaux, M. (2002). SRT lengthening: role of an alertness deficit in frontal damaged patients. Neuropsychologia 40, 2234-2241. doi: 10.1016/S0028-3932(02)00109-4

Godefroy, O., Roussel, M., Despretz, P., Quaglino, V., and Boucart, M. (2010). Agerelated slowing: perceptuomotor, decision, or attention decline? Exp. Aging Res. 36, 169-189. doi: 10.1080/03610731003613615

Habekost, T., Petersen, A., and Vangkilde, S. (2014). Testing attention: comparing the ANT with TVA-based assessment. Behav. Res. 46, 81-94. doi: 10.3758/s13428-013-0341-2

Hahn, E., Ta, T. M. T., Hahn, C., Kuehl, L. K., Ruehl, C., Neuhaus, A. H., et al. (2011). Test-retest reliability of Attention Network Test measures in schizophrenia. Schizophr. Res. 133, 218-222. doi: 10.1016/j.schres.2011.09.026

Hart, R. P., Wade, J. B., Calabrese, V. P., and Colenda, C. C. (1998). Vigilance performance in Parkinson's disease and depression. J. Clin. Exp. Neuropsychol. 20, 111-117. doi: 10.1076/1380-3395(199802)20:1;1-P;FT111

Henderson, L., and Dittrich, W. H. (1998). Preparing to react in the absence of uncertainty: I. new perspectives on simple reaction time. Br. J. Psychol. 89(Pt 4), 531-554. doi: 10.1111/j.2044-8295.1998.tb02702.x

Hommel, B., and Doeller, C. F. (2005). Selection and consolidation of objects and actions. Psychol. Res. 69, 157-166. doi: 10.1007/s00426-004-0171-Z

Ishigami, Y., Eskes, G. A., Tyndall, A. V., Longman, R. S., Drogos, L. L., and Poulin, M. J. (2016). The Attention Network Test-Interaction (ANT?I): reliability and validity in healthy older adults. Exp. Brain Res. 234, 815-827. doi: 10.1007/s00221-015-4493-4

Ishigami, Y., and Klein, R. M. (2010). Repeated measurement of the components of attention using two versions of the Attention Network Test (ANT): stability, isolability, robustness, and reliability. J. Neurosci. Methods 190, 117-128. doi: 10.1016/j.jneumeth.2010.04.019

Ishigami, Y., and Klein, R. M. (2011). Repeated measurement of the components of attention of older adults using the two versions of the attention network test: stability, isolability, robustness, and reliability. Front. Aging Neurosci. 3:17. doi: 10.3389/fnagi.2011.00017

Janculjak, D., Mubrin, Z., Brzovic, Z., Brinar, V., Barac, B., Palic, J., et al. (1999). Changes in short-term memory processes in patients with multiple sclerosis. Eur. J. Neurol. 6, 663-668. doi: 10.1046/j.1468-1331.1999.660663.x

Jones, S. A. H., Butler, B., Kintzel, F., Salmon, J. P., Klein, R., and Eskes, G. A. (2015). Measuring the components of attention using the Dalhousie Computerized Attention Battery (DalCAB). Psychol. Assess. 27, 1286-1300. doi: $10.1037 /$ pas0000148

Kim, H., Dinges, D. F., and Young, T. (2007). Sleep-disordered breathing and psychomotor vigilance in a community-based sample. Sleep 30, 1309-1316.

Krueger, C. E., Bird, A. C., Growdon, M. E., Jang, J. Y., Miller, B. L., and Kramer, J. H. (2009). Conflict monitoring in early frontotemporal dementia. Neurology 73, 349-355. doi: 10.1212/WNL.0b013e3181b04b24

Kurtz, M. M., Ragland, J. D., Bilker, W., Gur, R. C., and Gur, R. E. (2001). Comparison of the continuous performance test with and without working memory demands in healthy controls and patients with schizophrenia. Schizophr. Res. 48, 307-316. doi: 10.1016/S0920-9964(00)00060-8 
Leskin, L. P., and White, P. M. (2007). Attentional networks reveal executive function deficits in posttraumatic stress disorder. Neuropsychology 21, 275-284. doi: 10.1037/0894-4105.21.3.275

Lezak, M. D. (1995). Neuropsychological Assessment, 3rd Edn. New York, NY: Oxford University Press, Inc.

Llorente, A. M., Amado, A. J., Voigt, R. G., Berretta, M. C., Fraley, J. K., Jensen, C. L., et al. (2001). Internal consistency, temporal stability, and reproducibility of individual index scores of the Test of Variables of Attention in children with attention-deficit/hyperactivity disorder. Arch. Clin. Neuropsychol. 16, 535-546. doi: 10.1093/arclin/16.6.535

Lowe, C., and Rabbitt, P. (1998). Test/re-test reliability of the CANTAB and ISPOCD neuropsychological batteries: theoretical and practical issues. Neuropsychologia 36, 915-923. doi: 10.1016/S0028-3932(98)00036-0

Luks, T. L., Oliveira, M., Possin, K. L., Bird, A., Miller, B. L., Weiner, M. W., et al. (2010). Atrophy in two attention networks is associated with performance on a Flanker task in neurodegenerative disease. Neuropsychologia 48, 165-170. doi: 10.1016/j.neuropsychologia.2009.09.001

MacLeod, J. W., Lawrence, M. A., McConnell, M. M., Eskes, G. A., Klein, R. M., and Shore, D. I. (2010). Appraising the ANT: Psychometric and theoretical considerations of the Attention Network Test. Neuropsychology 24, 637-651. doi: 10.1037/a0019803

Messinis, L., Kosmidis, M. H., Tsakona, I., Georgiou, V., Aretouli, E., and Papathanasopoulos, P. (2007). Ruff 2 and 7 Selective Attention Test: Normative data, discriminant validity and test-retest reliability in Greek adults. Arch. Clin. Neuropsychol. 22, 773-785. doi: 10.1016/j.acn.2007.06.005

Middleton, L. E., Lam, B., Fahmi, H., Black, S. E., McIlroy, W. E., Stuss, D. T., et al. (2014). Frequency of domain-specific cognitive impairment in sub-actue and chronic stroke. NeuroRehabilitation 34, 305-312. doi: 10.3233/NRE-131030

Naatanen, R. (1982). Processing negativity: an evoked-potential reflection of selective attention. Psychol. Bull. 92, 605-640. doi: 10.1037/0033-2909.92.3.605

Nakayama, Y., Covassin, T., Schatz, P., Nogle, S., and Kovan, J. (2014). Examination of the test-retest reliability of a computerized neurocognitive test battery. Am. J. Sports Med. 42, 2000-2005. doi: 10.1177/0363546514535901

Petersen, S. E., and Posner, M. I. (2012). The attention system of the human brain: 20 years after. Annu. Rev. Neurosci. 35, 73-89. doi: 10.1146/annurev-neuro062111-150525

Poewe, W., Berger, W., Benke, T., and Schelosky, L. (1991). High-speed memory scanning in Parkinson's disease: adverse effects of levodopa. Ann. Neurol. 29, 670-673. doi: 10.1002/ana.410290616

Posner, M. I. (1980). Orienting of attention. Q. J. Exp. Psychol. 32, 3-25. doi: 10.1080/00335558008248231

Posner, M. I., Cohen, Y., and Rafal, R. D. (1982). Neural systems control of spatial orienting. Philos. Trans. R. Soc. Lond. B Biol. Sci. 298, 187-198. doi: 10.1098/rstb.1982.0081

Posner, M. I., and Petersen, S. E. (1990). The attention system of the human brain. Annu. Rev. Neurosci. 13, 25-42. doi: 10.1146/annurev.ne.13.030190.000325

Posner, M. I., Rothbart, M. K., Vizueta, N., Levy, K. N., Evans, D. E., Thomas, K. M., et al., (2002). Attentional mechanisms of borderline personality disorder. Proc. Natl. Acad. Sci. U.S.A. 99, 16366-16370. doi: 10.1073/pnas.252644699

Raymond, P. D., Hinton-Bayre, A. D., Radel, M., Ray, M. J., and Marsh, N. A. (2006). Test-retest norms and reliable change indices for the MicroCog battery in a healthy community population over 50 years of age. Clin. Neuropsychol. 20, 261-270. doi: 10.1080/13854040590947416

Rubinfeld, L., Kintzel, F., Jones, S. A. H., Butler, B., Klein, R., and Eskes, G. (2014, October). "Validity and reliability of the dalhousie computerized attention battery in healthy older adults," in Poster presented at the Department of Psychiatry $24^{\text {th }}$ Annual Research Day, Dalhousie University (Halifax, NS).

Salthouse, T. A. (2010). Is flanker-based inhibition related to age? Identifying specific influences of individual differences on neurocognitive variables. Brain Cogn. 73, 51-61. doi: 10.1016/j.bandc.2010.02.003

Secker, D. L., Merrick, P. L., Madsen, S., Melding, P., and Brown, R. G. (2004). Test-retest reliability of the ECO computerised cognitive battery for the elderly. Aging Neuropsychol. Cogn. 11, 51-57. doi: 10.1076/anec.11.1.51. 29361

Steinborn, M. B., and Langner, R. (2012). Arousal modulates temporal preparation under increased time uncertainty: evidence from higher-order sequential foreperiod effects. Acta Psychol. 139, 65-76. doi: 10.1016/j.actpsy.2011.10.010

Sternberg, S. (1966). High-speed scanning in human memory. Science 153, 652-654. doi: 10.1126/science.153.3736.652

Sternberg, S. (1969). Memory-scanning: mental processes revealed by reactiontime experiments. Am. Sci. 57, 421-457.

Stoquart-Elsankari, S., Bottin, C., Roussel-Pieronne, M., and Godefroy, O. (2010). Motor and cognitive slowing in multiple sclerosis: an attentional deficit? Clin. Neurol. Neurosurg. 112, 226-232. doi: 10.1016/j.clineuro.2009.11.017

Sturm, W., and Willmes, K. (2001). On the functional neuroanatomy of intrinsic and phasic alertness. Neuroimage 14, S76-S84. doi: 10.1006/nimg.2001.0839

Tabachnick, B. G., Fidell, L. S., and Osterlind, S. J. (2001). Using Multivariate Statistics. Pearson.

Tales, A., Haworth, J., Nelson, S., Snowden, R. J., and Wilcock, G. (2005). Abnormal visual search in mild cognitive impairment and Alzheimer's disease. Neurocase 11, 80-84. doi: 10.1080/13554790490896974

Torgalsbøen, A.-K., Mohn, C., Czajkowski, N., and Rund, B. R. (2015). Relationship between neurocognition and functional recovery in first-episode schizophrenia: results from the second year of the Oslo multi-follow-up study. Psychiatry Res. 227, 185-191. doi: 10.1016/j.psychres.2015.03.037

Treisman, A. M., and Gelade, G. (1980). A feature-integration theory of attention. Cogn. Psychol. 12, 97-136. doi: 10.1016/0010-0285(80)90005-5

Vallesi, A., Lozano, V. N., and Correa, A. (2013). Dissociating temporal preparation processes as a function of the inter-trial interval duration. Cognition 127, 22-30. doi: 10.1016/j.cognition.2012.11.011

Vallesi, A., McIntosh, A. R., and Stuss, D. T. (2009). Temporal preparation in aging: a functional MRI study. Neuropsychologia 47, 2876-2881. doi: 10.1016/j.neuropsychologia.2009.06.013

Van Ness, P. H., Towle, V. R., and Juthani-Mehta, M. (2008). Testing measurement reliability in older populations: methods for informaed discrimination in instrument selection and application. J. Health Aging, 20, 183-197. doi: 10.1177/0898264307310448

Wicklegren, W. A. (1977). Speed-accuracy trade off and information processing dynamics. Acta Psychol. 41, 67-85. doi: 10.1016/0001-6918(77)90012-9

Williams, L. M., Simms, E., Clark, C. R., Paul, R. H., Rowe, D., and Gordon, E. (2005). The test-retest reliability of a standardized neurocognitive and neurophysiological test battery: "neuromarker". Int. J. Neurosci. 115, 1605-1630. doi: 10.1080/00207450590958475

Wolfe, J. M. (1998). What can 1 million trials tell us about visual search? Psychol. Sci. 9, 33-39. doi: 10.1111/1467-9280.00006

Wöstmann, N. M., Aichert, D. S., Costa, A., Rubia, K., Möller, H.-J., and Ettinger, U. (2013). Reliability and plasticity of response inhibition and interference control. Brain Cogn. 81, 82-94. doi: 10.1016/j.bandc.2012.09.010

Zabel, T. A., von Thomsen, C., Cole, C., Martin, R., and Mahone, E. M. (2009). Reliability concerns in the repeated computerized assessment of attention in children. Clin. Neuropsychol. 23, 1213-1231. doi: 10.1080/138540409028 55358

Conflict of Interest Statement: The authors declare that the research was conducted in the absence of any commercial or financial relationships that could be construed as a potential conflict of interest.

Copyright (c) 2016 Jones, Butler, Kintzel, Johnson, Klein and Eskes. This is an openaccess article distributed under the terms of the Creative Commons Attribution License (CC BY). The use, distribution or reproduction in other forums is permitted, provided the original author(s) or licensor are credited and that the original publication in this journal is cited, in accordance with accepted academic practice. No use, distribution or reproduction is permitted which does not comply with these terms. 